Article

\title{
Process Design of the Antioxidant Shuidouchi and Its Effect on Preventing Dextran Sulfate Sodium (DSS)-Induced Colitis in Mice via Antioxidant Activity
}

\author{
Jing Zhang ${ }^{1,2, \dagger}$, Qin $\mathrm{Li}^{2,3,+}$, Yang Wei ${ }^{2}$, Xingyao Long ${ }^{2,4}$, Jianfei $\mathrm{Mu}^{2,5}$, Yanni Pan ${ }^{2,4}$ and \\ Xin Zhao ${ }^{2, *(\mathbb{D})}$ \\ 1 Environment and Quality Inspection College, Chongqing Chemical Industry Vocational College, \\ Chongqing 401228, China; zjinger0810@126.com \\ 2 Chongqing Collaborative Innovation Center for Functional Food, Chongqing University of Education, \\ Chongqing 400067, China; 13594018454@163.com (Q.L.); grace951006@163.com (Y.W.); \\ longyaoyao@foods.ac.cn (X.L.); mujianfei@foods.ac.cn (J.M.); panyanni@foods.ac.cn (Y.P.) \\ 3 College of Life Sciences, Chongqing Normal University, Chongqing 400047, China \\ 4 Department of Food Science and Biotechnology, Cha University, Seongnam 13488, Gyeongghi-do, Korea \\ 5 College of Food Science, Southwest University, Chongqing 400715, China \\ * Correspondence: zhaoxin@cque.edu.cn; Tel.: +86-23-6265-3650 \\ + These authors contributed equally to this work.
}

Received: 28 November 2018; Accepted: 17 December 2018; Published: 20 December 2018

\begin{abstract}
Shuidouchi is a traditionally fermented soybean product in China. Shuidouchi production requires a variety of processes; however, the production process has not been standardized. It can be developed into high-quality products with enhanced health effects by improving the design of its fermentation process and increasing the content of its active ingredients. In this study, a single-factor experiment was conducted that established different process conditions to determine the fermentation conditions that achieve the highest content of active ingredients and the best in vitro antioxidant effect. The effect of Shuidouchi on the prevention of dextran sulfate sodium-induced colitis in mice was also observed. The obtained results indicated that the optimal process conditions involved soaking for $12 \mathrm{~h}$, placement in a glass container, and fermentation at $35^{\circ} \mathrm{C}$ for $48 \mathrm{~h}$. Shuidouchi that was fermented under such conditions had the highest level of soybean isoflavones and exerted greater antioxidant effects than if fermented under other conditions. The Shuidouchi extract (soaking twice the quantity of water for $12 \mathrm{~h}$, placing in a glass container, and fermenting at $35^{\circ} \mathrm{C}$ for $48 \mathrm{~h}$ ) obtained by using the optimal fermentation process can prevent the shortening of the colon and increase the weight-to-length ratio of the colon that is caused by colitis. Shuidouchi extraction not only effectively reduces the disease activity index and the levels of serum endothelin (ET), substance P (SP), and interleukin-10 (IL-10), it also increases the levels of somatostatin (SS), vasoactive intestinal peptide (VIP), and interleukin-2 (IL-2) of mice with colitis. In addition, Shuidouchi extraction increased the levels of glutathione (GSH) and superoxide dismutase (SOD) in colitis mice; in contrast, Shuidouchi decreased the levels of myeloperoxidase (MPO) and malondialdehyde (MDA) in the colon of mice with colitis. Further detection of mRNA in colon tissues showed that Shuidouchi extraction can upregulate the expression of neuronal nitric oxide synthase (nNOS), endothelial nitric oxide synthase (eNOS), c-Kit, and the stem cell factor (SCF). Furthermore, it can downregulate the expression of inducible nitric oxide synthase (iNOS), interleukin-8 (IL-8), and C-X-C chemokine receptor type 2 (CXCR2) in the colon of mice with colitis. Further experimental results showed that Shuidouchi could reduce the protein expression of interleukin 6 (IL-6), IL-12, and tumor necrosis factor- $\alpha$ (TNF- $\alpha$ ) in colitic mice. Therefore, the improved processing of Shuidouchi inhibits colitis, which is directly related to the high content of soybean isoflavones.
\end{abstract}

Keywords: Shuidouchi; antioxidant; colitis; gene; mice 


\section{Introduction}

Douchi is a traditional fermented soybean product in China with both desirable taste and functional effects [1]. Shuidouchi is a type of bacterial Douchi, which is a type of seasoning that is fermented by bacterial action, which has a history of use as seasoning or as a dish for thousands of years. It was used not only as a simple food but also as a type of medicine in ancient Chinese medical books. Shuidouchi was also used as a traditional Chinese medicine with appetite-stimulating effects that strengthens the spleen, eliminates heat, and exerts detoxifying effects [2]. Modern scientific research methods have identified many functional ingredients in Shuidouchi, which confer antioxidant, antimutagenic, and anticancer effects of soybean products (e.g., Douchi, Shuidouchi, and soy sauce) [3]. However, studies on the physiological activity of Shuidouchi have rarely been conducted.

Chinese Shuidouchi, Japanese Natto, and Korean Koji sauce are typical examples of food from bacterially fermented soybeans. Japan was the first to isolate and identify the fermentation strain of Natto and simultaneously develop purely fermented Natto products after an in-depth study of the physiological activities of Natto. The study reported that Natto exhibits antioxidant, anti-inflammatory, and anticancer effects [4-6]. These three bacterially fermented soybean foods (Chinese Shuidouchi, Japanese Natto, and Korean Chungkukjang) are all produced with similar technology. Japanese Natto and Korean Chungkukjang have been fully studied and reported to date, including process improvement, functional effects, and extraction of active ingredients $[7,8]$. In China, only a few preliminary studies have been conducted on Shuidouchi, indicating its anti-inflammatory and anti-cancer effects [7]. The specific mechanism and process improvement of Shuidouchi have not been explored sufficiently.

Previous studies showed that the quality of soybean sauce was related to numerous factors, such as the fermentation bacteria, the amount of water for soaking the soybeans, the fermentation time, fermentation temperature, and the time after fermentation $[9,10]$. In addition, the fermentation container is also one of the factors to affect the quality of fermented soybean products [11]. A study confirmed that the quality of Korean Chungkukjang was related to these fermentation factors [7]. In China, the effects of single factors, such as fermentation temperature, fermentation time, and fermentation container on the quality of Shuidouchi were partially confirmed $[2,9,12]$. The optimal combination of these factors and the optimal fermentation process is the focus of this study.

Intestinal health plays an important role for maintaining high quality of life. Digestive absorption, metabolism, and mucosal immunity can decline with age, and the number of probiotics in the digestive system can rapidly decrease. Intestinal canal aging can simultaneously lead to difficulty in defecation, flatulence, dyspepsia, and accumulation of vivotoxins, which, among other issues, influence human health [13]. Almost 95\% of the Chinese suffer from intestinal diseases, which severely influences their health and quality of life. Constipation, colitis, and colon cancer are critical intestinal diseases posing considerable risks for human health [14].

Shuidouchi is rich in thrombolytic ingredients, soybean polypeptides, soybean oligosaccharides, protein melanin, soybean saponins, complex digestive enzymes, active isoflavones, vitamin B1, microbial B2, vitamin C, vitamin E, amino acids, and further bioactive substances $[15,16]$. The active ingredients of soybean polypeptides, soybean oligosaccharides, protein melanin, soybean saponins, complex digestive enzymes, active isoflavones in Shuidouchi have been suggested to alleviate constipation and prevent both colitis and colon cancer [2,3]. More active substances could be produced by improving the fermentation process of Shuidouchi. These active ingredients would be more conducive to the protection of the intestinal tract and the prevention of colitis. The purpose of this study is to explore the mechanism underlying Shuidouchi efficacy using molecular biology technologies, improve the preventive effect of Shuidouchi on colitis, and to accumulate a solid theoretical basis for the further development of functional Shuidouchi. 


\section{Materials and Methods}

\subsection{Fermentation of Shuidouchi}

Shuidouchi was fermented at different temperatures: $100 \mathrm{~g}$ of soybeans (Zhongnong Xianheng Agricultural Development Co., Ltd., Beijing, China) were weighed in $200 \mathrm{~mL}$ distilled water for $12 \mathrm{~h}$ and the soaked soybeans were boiled in a high-pressure sterilizing pot for $1 \mathrm{~h}$. The boiled soybeans were cooled to $30^{\circ} \mathrm{C}, 35^{\circ} \mathrm{C}$, and $40{ }^{\circ} \mathrm{C}$, and then fermented in a glass container for $48 \mathrm{~h}$ (Figure $1 \mathrm{~A}$ ).

Shuidouchi was fermented for different durations: $100 \mathrm{~g}$ of soybeans were weighed in $200 \mathrm{~mL}$ distilled water for $12 \mathrm{~h}$ and the soaked soybeans were boiled in a high-pressure sterilizing pot for $1 \mathrm{~h}$. The boiled soybeans were cooled to $35^{\circ} \mathrm{C}$ and then fermented in a glass container for 24,48 , and $72 \mathrm{~h}$ (Figure 1B).

Shuidouchi was fermented using different amounts of soybeans: $100 \mathrm{~g}$ of soybeans were weighed in 100, 200, and $300 \mathrm{~mL}$ distilled water for $12 \mathrm{~h}$. The soaked soybeans were boiled in a high-pressure sterilizing pot for $1 \mathrm{~h}$. The boiled soybeans were cooled to $35^{\circ} \mathrm{C}$ and then fermented in a glass container for $48 \mathrm{~h}$ (Figure 1C).

Shuidouchi was fermented in different containers: $100 \mathrm{~g}$ of soybeans were weighed in $200 \mathrm{~mL}$ distilled water for $12 \mathrm{~h}$. The soaked soybeans were boiled in a high-pressure sterilizing pot for $1 \mathrm{~h}$. The boiled soybeans were cooled to $35^{\circ} \mathrm{C}$ and then fermented in ceramic, glass, or metal containers for 48 h (Figure 1D).
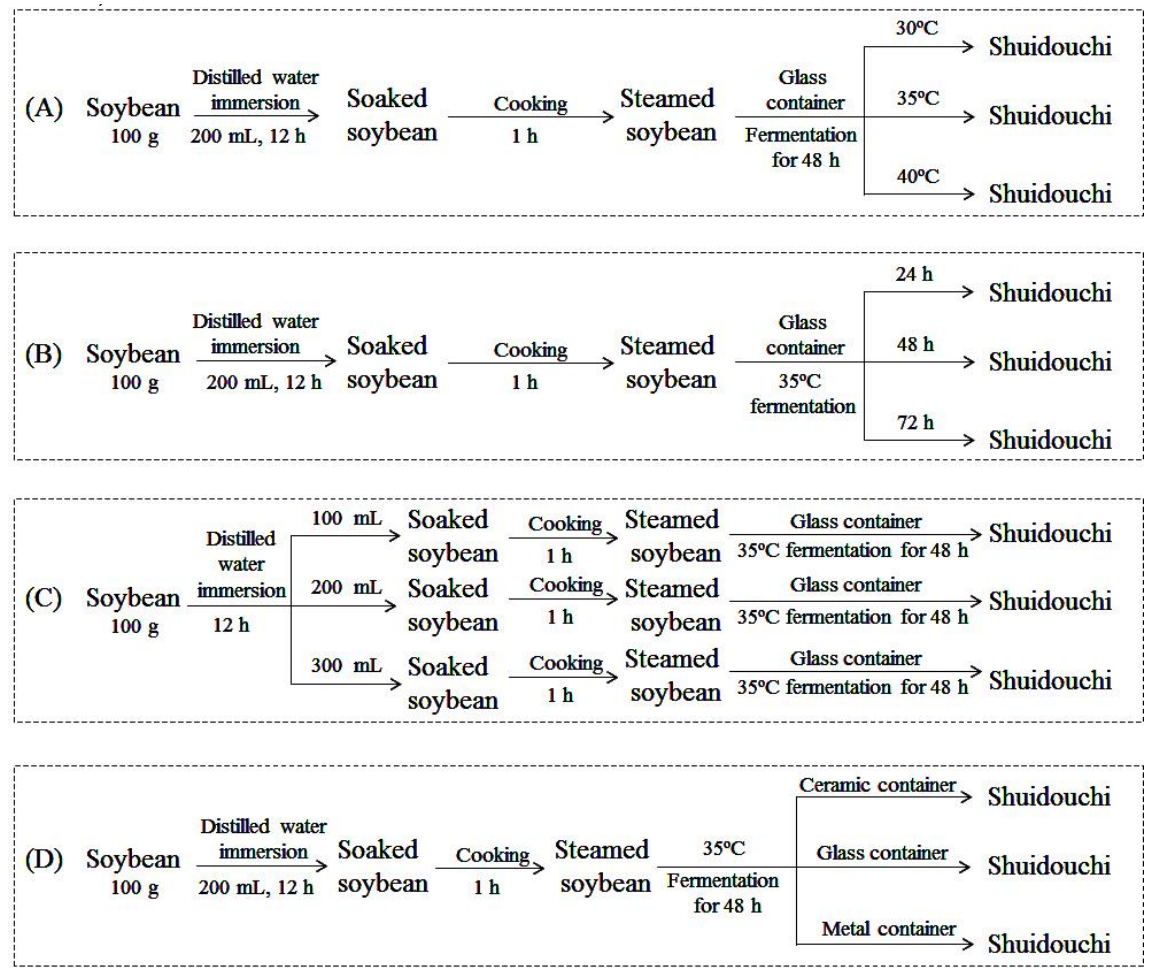

Figure 1. Technological design of Shuidouchi. (A) Soybeans fermented at different temperatures; (B) Soybeans fermented for different durations; (C) Soybeans fermented in different quantities of soaking water; and, (D) Soybeans fermented in different containers.

\subsection{Shuidouchi Extraction}

Shuidouchi was frozen-dried and crushed, and then the Shuidouchi powder was extracted by a 20-fold diluted (w/v) ethanol for $12 \mathrm{~h}$. The extract was filtered, the filtrate was retained, and the filtrate residue was extracted again by the above method [2]. 


\subsection{Determination of Free Radical Scavening Rate of Shuidouchi by DPPH}

Reagents (Shanghai Jinsui Biotechnology Co., Ltd., Shanghai, China) (Table 1) were added into the extracted Shuidouchi, and for a final reaction, $200 \mu \mathrm{l}$ of DPPH (2,2-Diphenyl-1-picrylhydrazyl) solution (Shanghai Jinsui Biotechnology Co., Ltd., Shanghai, China) $(60 \mu \mathrm{M})$ was added to wells of 96-well plate containing $50 \mu \mathrm{l}$ of Shuidouchi extract, which was stored in the dark for $90 \mathrm{~min}$. The absorbance was measured at $517 \mathrm{~nm}$ and the radical scavenging rate was calculated [15]. DPPH (\%) was expressed as A3-(A1-A2) / A3 $\times 100$. The calculation of $\mathrm{IC}_{50}$ when the DPPH radical was scavenged up to $50 \%$ was conducted according to the $\mathrm{T}$ logarithm $(\mathrm{X})$ of the concentration of the DPPH radical plotted by the clearance rate $(\mathrm{Y})$; a linear equation was thus obtained. The $\mathrm{IC}_{50}$ was derived from the linear equation.

Table 1. DPPH (2,2-Diphenyl-1-picrylhydrazyl) determination method.

\begin{tabular}{cc}
\hline No. & Sample reaction System \\
\hline $\mathrm{A}_{1}$ & $3.9 \mathrm{~mL}$ DPPH solution $+100 \mu \mathrm{L}$ sample solution \\
$\mathrm{A}_{2}$ & $3.9 \mathrm{~mL}$ anhydrous ethanol $+100 \mu \mathrm{L}$ sample solution \\
$\mathrm{A}_{3}$ & $3.9 \mathrm{~mL}$ DPPH solution $+100 \mu \mathrm{L} 80 \%$ methanol solution \\
\hline
\end{tabular}

\subsection{Determination of Free Radical Scavenging Rate of Shuidouchi by ABTS ${ }^{+}$}

Reagents (Table 2) were added to the Shuidouchi extract, and a final reaction solution $(200 \mu \mathrm{L})$ was added to a 96-well plate after storage in the dark for $6 \mathrm{~min}$. Absorbance was measured at $734 \mathrm{~nm}$. The radical scavenging rate was also calculated. The computational formula for the 2,2'-azino-bis(3-ethylbenzthiazoline) 6-sulphonic acid $\left(\mathrm{ABTS}^{+}\right)$radical scavenging rate is $\mathrm{ABTS}^{+}(\%)=\mathrm{A} 3-(\mathrm{A} 1-\mathrm{A} 2) / \mathrm{A} 3 \times 100$. The calculation of the required extract concentration, which is an $\mathrm{ABTS}^{+}$free radical, reached up to $50 \%$. The elimination rate $(\mathrm{Y})$ was plotted with the logarithm $(\mathrm{X})$ of the concentration of the extract and its linear equation was obtained. The $\mathrm{IC}_{50}$ was determined in accordance with the linear equation.

Table 2. $\mathrm{ABTS}^{+}$(2,2'-azino-bis(3-ethylbenzthiazoline) 6-sulphonic acid) determination.

\begin{tabular}{cc}
\hline No. & Sample Reaction System \\
\hline $\mathrm{A}_{1}$ & $5 \mathrm{~mL}$ ABTS reaction solution $+200 \mu \mathrm{L}$ sample solution \\
$\mathrm{A}_{2}$ & $5 \mathrm{~mL}$ anhydrous ethanol $+200 \mu \mathrm{L}$ sample solution \\
$\mathrm{A}_{3}$ & $5 \mathrm{~mL}$ ABTS solution $+200 \mu \mathrm{L} 80 \%$ methanol solution \\
\hline
\end{tabular}

\subsection{Determination of the Free Radical Scavenging Rate Of Shuidouchi by the Hydroxyl Radical Method}

Reagents (Table 3) were added to the Shuidouchi extract sample and heated for $30 \mathrm{~min}$ in a water bat at $37^{\circ} \mathrm{C}$. The final reaction solution $(200 \mu \mathrm{L})$ was added to the 96 -well plate. Absorbance was measured at $510 \mathrm{~nm}$ and the free radical scavenging rate was calculated. The computational formula for the hydroxyl radical scavenging rate is $\mathrm{OH}(\%)=\mathrm{A} 3-(\mathrm{A} 1-\mathrm{A} 2) / \mathrm{A} 3 \times 100$. The required extraction concentration $\left(\mathrm{IC}_{50}\right)$ when hydroxyl radicals were cleared to $50 \%$ was calculated by plotting the elimination rate $(\mathrm{Y})$ with the logarithm $(\mathrm{X})$ of the extract concentration, and the linear equation was obtained. The $\mathrm{IC}_{50}$ was obtained based on this linear equation.

Table 3. Hydroxyl radical determination.

\begin{tabular}{cc}
\hline No. & Sample Reaction System \\
\hline $\mathrm{A}_{1}$ & $300 \mu \mathrm{L} 80 \%$ methanol solution $+2.0 \mathrm{~mL} \mathrm{FeSO}_{4}+1.0 \mathrm{~mL}$ salicylic acid ethanol solution $+1.0 \mathrm{~mL} \mathrm{H}_{2} \mathrm{O}_{2}$ \\
$\mathrm{~A}_{2}$ & $300 \mu \mathrm{L}$ sample solution $+2.0 \mathrm{~mL} \mathrm{FeSO}_{4}+1.0 \mathrm{~mL}$ salicylic acid ethanol solution $+1.0 \mathrm{~mL} \mathrm{H}_{2} \mathrm{O}_{2}$ \\
$\mathrm{~A}_{3}$ & $300 \mu \mathrm{L}$ sample solution $+2.0 \mathrm{~mL} \mathrm{FeSO}_{4}+1.0 \mathrm{~mL}$ salicylic acid ethanol solution $+1.0 \mathrm{~mL} 80 \%$ methanol solution \\
\hline
\end{tabular}

\subsection{Determination of Soybean Isoflavones in Shuidouchi}

$10.2 \mathrm{mg}$ of genistein standard solution (Shanghai Yuanye Biotechnology Co., Ltd., Shanghai, China) was precisely weighed and poured into a $50 \mathrm{~mL}$ volumetric flask. $0.01 \mathrm{~mol} / \mathrm{L} \mathrm{NaOH}$ (Sinopharm 
Chemical Reagent Co., Ltd., Shanghai, China) solution was then added to achieve a volume of $50 \mathrm{~mL}$. After the configuration of the base solution, 1.0, 2.0, 3.0, 4.0, and $5.0 \mathrm{~mL}$ solutions were precisely extracted and placed in a $100 \mathrm{~mL}$ volumetric flask. Subsequently, $0.01 \mathrm{~mol} / \mathrm{L} \mathrm{NaOH}$ solution was added to a $100 \mathrm{~mL}$ scale. The absorbance values of all solutions at $271 \mathrm{~nm}$ were measured with a $0.01 \mathrm{~mol} / \mathrm{L} \mathrm{NaOH}$ blank solution. A standard curve was generated, with the absorbance values $(\mathrm{Y})$ on the ordinate and the concentrations of genistein $(\mu \mathrm{L} / \mathrm{mL})$ on the abscissa. After the standard curve was determined, the Shuidouchi sample was dissolved in a $0.01 \mathrm{~mol} / \mathrm{L} \mathrm{NaOH}$ solution and the absorbance value was determined at $271 \mathrm{~nm}$. The standard curve of the soybean isoflavones content was ultimately obtained (genistein meter, Figure 2).

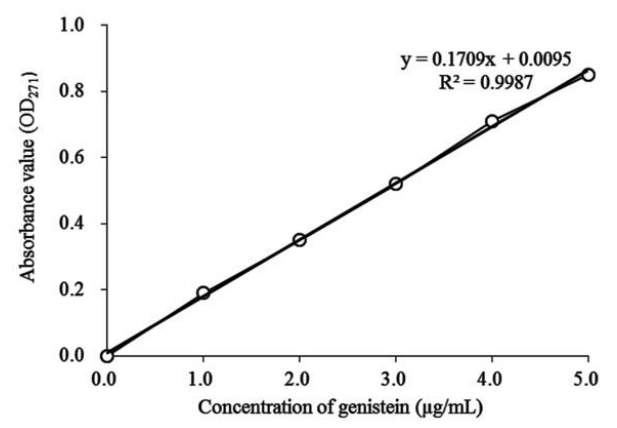

Figure 2. Standard curve of soybean isoflavone content (genistein).

\subsection{Animal Experiment}

A total of 50 Kunming mice (seven weeks old, 25 male and 25 female) were kept at $25 \pm 2{ }^{\circ} \mathrm{C}$, $50 \pm 5 \%$ in a feeding environment with relative humidity and with light and shade indoors adjusted alternately every $12 \mathrm{~h}$. A second set of 50 mice with similar body weights were randomly divided into five groups: normal group, control group, SDC-L group (mice were fed with low-concentration $(2 \mathrm{~g} / \mathrm{kg}$ ) Shuidouchi extract by gavage), SDC-H group (mice were fed via gavage with high-concentration $(4 \mathrm{~g} / \mathrm{kg})$ Shuidouchi extract), and sulfasalazine group (positive control group). After the onset of the experiment, mice in each group were freely fed with the respective diet. Except for mice in the normal group, all other mice received $2 \%(\mathrm{w} / \mathrm{v})$ DSS solution as drinking water during the third week. After feeding distilled water for one week, all other mice except for the normal group received $4 \%$ $(\mathrm{w} / \mathrm{v})$ DSS solution as drinking water during the fifth week. Except for the third and fifth weeks, all mice received distilled water as drinking water for the rest of the time $[16,17]$. During the entire experimental duration of five weeks, the SDC-L and SDC-H groups received 2 and $4 \mathrm{~g} / \mathrm{kg}$ of extract of Shuidouchi daily after the optimization of crafts. The mice in the sulfasalazine group were fed with $20 \mathrm{mg} / \mathrm{kg}$ sulfasalazine daily. All mice fasted for $24 \mathrm{~h}$ on Day 35 and were killed on Day 36. The colon length and weight of each mouse were measured and the colon weight/colon length index was then calculated. The disease activity index (DAI) of each mouse was simultaneously calculated, as follows: DAI $=($ fraction of weight loss + fraction of stool shape + fraction of stool occult blood) $/ 3$ (Table 4$)$. The blood and colon tissues were also collected for later use. The protocol for these experiments was approved by the Animal Ethics Committee of the Chongqing Medical University under the animal permit number SYXK (Yu) 2018-0003.

Table 4. Disease activity index (DAI) scoring standard.

\begin{tabular}{cccc}
\hline Weight Loss (\%) & Shape of Stool & Occult Blood/Bloody Stool & Score \\
\hline 0 & Normal & Negative & 0 \\
$1-5$ & Soft stool & Negative & 1 \\
$6-10$ & Soft stool & Occult blood & 2 \\
$11-15$ & Diarrhea & Occult blood & 3 \\
$>15$ & Diarrhea & Blood stool & 4 \\
\hline
\end{tabular}


2.8. Determination of Endothelin (Et), Somatostatin (Ss), Substance P (Sp), and Vasoactive Intestinal Peptide (Vip) and Levels of Serum in Mice

Serum was obtained from mice by centrifugation (4500 r/min, $15 \mathrm{~min}$ ). The endothelin (ET-1), somatostatin (SS), substance P (SP), and vasoactive intestinal peptide (VIP) levels in serum were determined using the respective kits (Abcam, Cambridge, MA, USA) [18].

\subsection{Determination of Interleukin (IL)-2 and Interleukin-10 (IL-10) Cytokines of Serum in Mice}

Serum was obtained by centrifugation of the mouse plasma using the 2.8 method. The interleukin (IL)-2 and IL-10 cytokine levels in serum were then determined using the respective kits (Abcam, Cambridge, MA, USA) [18].

2.10. Determination of Malondialdehyde, Myeloperoxidase, Superoxide Dismutase, and Glutathione Levels in the Colon Tissue of Mice

The colon tissue of mice and normal saline were mixed at a mass ratio of 1:9. The colon tissue was then homogenized by ultrasonic pulverization, and the levels of myeloperoxidase (MPO), superoxide dismutase (SOD), glutathione (GSH), and malondialdehyde (MDA) in the colon tissue were determined while using the respective kits (Nanjing Jiancheng Bioengineering Institute, Nanjing City, China) [18].

\subsection{Detection of mRNA Expression in Colon Tissue of Mice by qPCR}

The colon tissue of mice was homogenized, and RNA TRIzol Reagent (Invitrogen, Carlsbad, CA, USA) was used to extract the total RNA, which was then diluted to $1 \mu \mathrm{g} / \mu \mathrm{L}$. The diluted RNA solution of $5 \mu \mathrm{L}$ was obtained using a reverse transcription kit and the cDNA template was obtained. Subsequently, $2 \mu \mathrm{L}$ of the cDNA template was mixed with $10 \mu \mathrm{L}$ SYBR Green PCR (polymerase chain reaction) Master Mix and $1 \mu \mathrm{L}$ upstream and downstream primers (Thermo Fisher Scientific, Waltham, MA, USA) (Table 5). A total of 40 cycles were conducted after which the reaction conditions were as follows: $95^{\circ} \mathrm{C}, 60 \mathrm{~s} ; 95^{\circ} \mathrm{C}, 15 \mathrm{~s} ; 55^{\circ} \mathrm{C}, 30 \mathrm{~s}$; and, $7{ }^{\circ} \mathrm{C}, 35 \mathrm{~s}$ (StepOnePlus Real-Time PCR System, Thermo Fisher Scientific, Waltham, MA, USA). Relative gene expression was calculated using the $2^{-\Delta \Delta \mathrm{Ct}}$ method, using glyceraldehyde-3-phosphate dehydrogenase (GAPDH) as internal reference [17].

Table 5. Sequences of primers used.

\begin{tabular}{|c|c|}
\hline Gene Name & Sequences \\
\hline \multirow{2}{*}{ nNOS } & Forward: 5'-GAG AGG ATT CTG AAG ATG AGG-3' \\
\hline & Reverse: 5'-TTG CTA ATG AGG GAG TTG TTC-3' \\
\hline \multirow{2}{*}{ eNOS } & Forward: 5'-TGT TTG TCT GCG GCG ATG T-3' \\
\hline & Reverse: 5'-GGG TGC GTA TGC GGC TTG TC-3' \\
\hline iNOS & $\begin{array}{l}\text { Forward: 5'-CAT TGG AAG TGA AGC GTT TCG-3' } \\
\text { Reverse: } 5^{\prime} \text {-CAC AGA ACT GAG GGT ACA-3' }\end{array}$ \\
\hline \multirow{2}{*}{ c-Kit } & Forward: 5'-CATAGCCCAGGTAAAGCACAAT-3' \\
\hline & Reverse: 5'-GAACACTCCAGAATCGTCAACTC-3' \\
\hline \multirow{2}{*}{ SCF } & Forward: 5'-TCAGGGACTACGCTGCGAAAG-3' \\
\hline & Reverse: $5^{\prime}$-AAGAGCTGGCAGACCGACTCA-3' \\
\hline \multirow{2}{*}{ IL-8 } & Forward: 5'-CTAGGCATCTTCGTCCGTCC-3' \\
\hline & Reverse: 5'-TTGGGCCAACAGTAGCCTTC-3' \\
\hline CXCR2 & $\begin{array}{l}\text { Forward: 5'-TCTGCTCACAAACAGCGTCGTA-3' } \\
\text { Reverse: } \text { 5'-GAGTGGCATGGGACAGCATC-3' }^{\prime}\end{array}$ \\
\hline GAPDH & $\begin{array}{l}\text { Forward: 5'-TGC ACC ACC AAC TGC TTA G-3' } \\
\text { Reverse: } 5^{\prime} \text {-GAT GCA GGG ATG ATG TTC- } 3^{\prime}\end{array}$ \\
\hline
\end{tabular}

nNOS: neuronal nitric oxide synthase; eNOS: endothelial nitric oxide synthase; iNOS: inducible nitric oxide synthase; SCF: stem cell factor; IL-8: interleukin 8; CXCR2: C-X-C chemokine receptor type 2; GAPDH: glyceraldehyde-3-phosphate dehydrogenase. 


\subsection{Western Blot Analysis}

$100 \mathrm{mg}$ colon tissue was homogenized with $1 \mathrm{~mL}$ RIPA and $10 \mu \mathrm{L}$ PMSF (phenylmethylsulfonyl fluoride) (Thermo Fisher Scientific); then, the mixture was centrifuged at $12000 \mathrm{r} / \mathrm{min}$ for $5 \mathrm{~min}$. The intermediate protein layer solution was removed. A BCA protein quantitative kit (Thermo Fisher Scientific) was used to quantify proteins. The samples of each group were diluted to $50 \mathrm{~g} / \mathrm{mL}$ and then the diluted proteins were mixed with sample buffer at $4: 1$ and heated for $5 \mathrm{~min}$ at $100{ }^{\circ} \mathrm{C}$. Acrylamide, resolving buffer, starcking buffer, ditilled water, 10\% APS (ammonium persulfate), and TEMED (tetramethylethylenediamine, Thermo Fisher Scientific) were mixed proportionally to form an SDS-PAGE (sodium dodecyl sulfate polyacrylamide gel electropheresis) (Thermo Fisher Scientific) separating and concentrating glue, which was poured into the runner board for later useage. The prestained protein ladder and samples were put into the sample holes of the rubber sheet, and then the loaded SDS-PAGE gel was subjected to $50 \mathrm{~min}$ vertical gel electrophoresis. The PVDF (polyvinylidene fluoride) membrane was activated by methanol for $1 \mathrm{~min}$ and then the transmembrane was closed by TBST (tris buffered saline tween) solution containing $5 \%$ skim milk for $1 \mathrm{~h}$. After closure, the PVDF membrane was washed by TBST, the primary antibodies (IL-6, IL-12, and TNF- $\alpha$, Thermo Fisher Scientific) were incubated at $25^{\circ} \mathrm{C}$ for $2 \mathrm{~h}$, and the secondary antibody was incubated at $25^{\circ} \mathrm{C}$ for $1 \mathrm{~h}$. Finally, Supersignal West Pico PLUS was used to spray the PVDF film, followed by placin into iBright FL1000 (Thermo Fisher Scientific) for observation [17].

\subsection{Statistical Analysis}

The averages of the results of three parallel experiments were calculated. The SAS9.1 statistical software (SAS Institute Inc., Cary, NC, USA) was used for data analysis, and one-way ANOVA according to Duncan's multiple-range test was conducted to determine statistical significance.

\section{Results}

\subsection{Comparison of Soybean Isoflavone Contents of Shuidouchi Fermented at Different Temperatures}

The soybean isoflavone contents in Shuidouchi extract fermented at $30{ }^{\circ} \mathrm{C}, 35{ }^{\circ} \mathrm{C}$, and $40{ }^{\circ} \mathrm{C}$ were $42.52,58.87$, and $46.33 \mathrm{mg} / \mathrm{g}$, respectively, which was in accordance with the standard curve $\mathrm{Y}=0.1709 \mathrm{X}+0.0095$ (Figure 2). With the same determination method, the unfermented soybean showed a soybean isoflavone content of $33.71 \mathrm{mg} / \mathrm{g}$ (Figure 3).

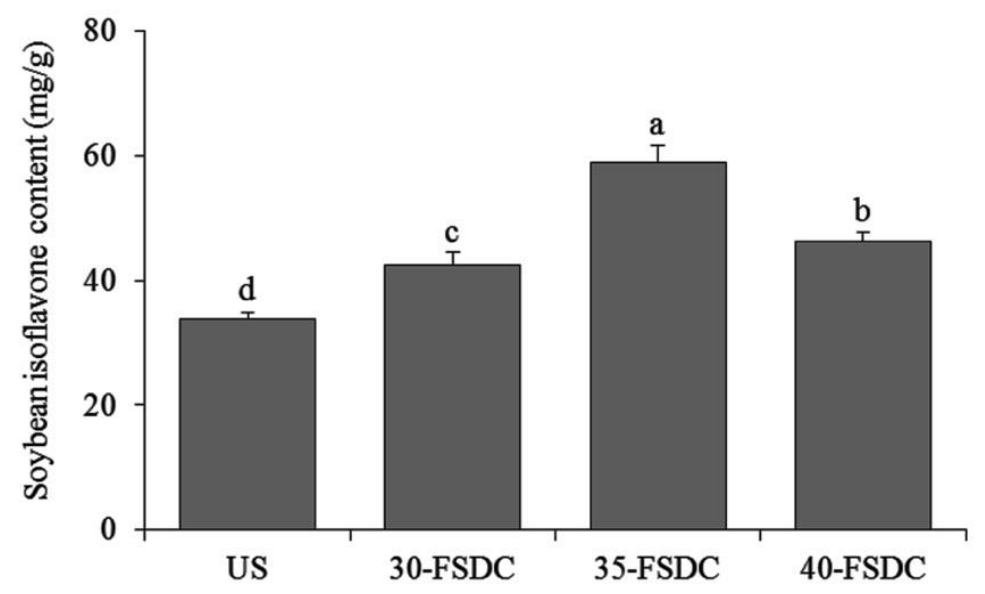

Figure 3. Soybean isoflavone contents of Shuidouchi fermented at different temperatures. ${ }^{\mathrm{a}-\mathrm{c}}$ Mean values with different letters indicate significant differences $(p<0.05)$. US: unfermented soybean; 30-FSDC (fermented Shuidouchi): $30{ }^{\circ} \mathrm{C}$ fermented Shuidouchi; $35-F S D C: 35^{\circ} \mathrm{C}$ fermented Shuidouchi; 40-FSDC: $40^{\circ} \mathrm{C}$ fermented Shuidouchi. 


\subsection{Comparison of Antioxidant Effects of Shuidouchi after Fermentation at Different Temperatures}

The results of Figure 4 and Table 6 indicate that, under the same fermentation conditions (specifically, the same concentration), the DPPH, $\mathrm{ABTS}^{+}$, and hydroxyl radical scavenging capacities of Shuidouchi extract fermented at $35^{\circ} \mathrm{C}$ exceed those fermented at $30^{\circ} \mathrm{C}$ and $40^{\circ} \mathrm{C}$. Further calculation confirmed that the $\mathrm{IC}_{50}$ of Shuidouchi extract fermented at $35^{\circ} \mathrm{C}$ was significantly lower than those of Shuidouchi extracts fermented at both $30{ }^{\circ} \mathrm{C}$ and $40{ }^{\circ} \mathrm{C}$. Despite the decreased concentrations, Shuidouchi that was fermented at $35^{\circ} \mathrm{C}$ could exert the same effect and achieved better antioxidant effects as those fermented at $30^{\circ} \mathrm{C}$ and $40^{\circ} \mathrm{C}$, respectively.
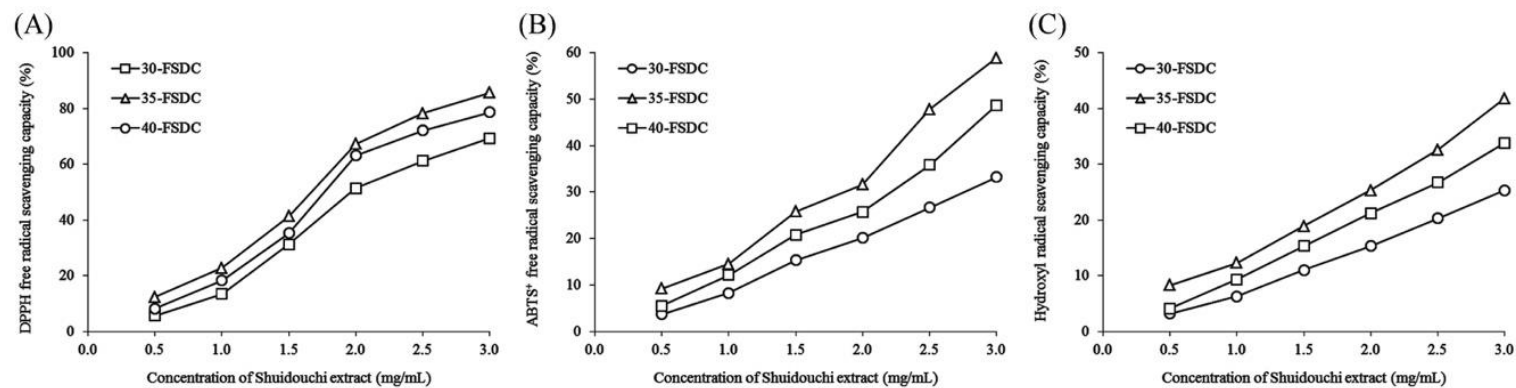

Figure 4. DPPH (2,2-Diphenyl-1-picrylhydrazyl) (A), $\mathrm{ABTS}^{+}$(2,2'-azino-bis(3-ethylbenzthiazoline) 6-sulphonic acid) (B), and hydroxyl (C) free radical scavenging capacity of Shuidouchi fermented at different fermentation temperatures. 30 -FSDC: $30^{\circ} \mathrm{C}$ fermented Shuidouchi; 35-FSDC: $35^{\circ} \mathrm{C}$ fermented Shuidouchi; 40-FSDC: $40^{\circ} \mathrm{C}$ fermented Shuidouchi.

Table 6. DPPH (A), $\mathrm{ABTS}^{+}$(B), and hydroxyl (C) free radical scavenging capacity of Shuidouchi at different fermentation temperatures.

\begin{tabular}{cllc}
\hline Type & Group & Linear regression Equation & IC $_{\mathbf{5 0}}(\mathbf{m g} / \mathbf{m L})$ \\
\hline \multirow{2}{*}{ DPPH free radical } & 30-FSDC & $\mathrm{Y}=27.514 \mathrm{X}-9.4667 \mathrm{R}^{2}=0.978$ & $2.06 \pm 0.03^{\mathrm{a}}$ \\
scavenging capacity & 35-FSDC & $\mathrm{Y}=31.937 \mathrm{X}-4.64 \mathrm{R}^{2}=0.9719$ & $1.71 \pm 0.03^{\mathrm{c}}$ \\
& 40-FSDC & $\mathrm{Y}=30.931 \mathrm{X}-8.2133 \mathrm{R}^{2}=0.9624$ & $1.88 \pm 0.02^{\mathrm{b}}$ \\
\hline \multirow{2}{*}{ ABTS $^{+}$free radical } & 30-FSDC & $\mathrm{Y}=11.857 \mathrm{X}-2.8667 \mathrm{R}^{2}=0.997$ & $4.46 \pm 0.02^{\mathrm{a}}$ \\
scavenging capacity & 35-FSDC & $\mathrm{Y}=20.24 \mathrm{X}-4.12 \mathrm{R}^{2}=0.9767$ & $2.67 \pm 0.03^{\mathrm{c}}$ \\
& 40-FSDC & $\mathrm{Y}=16.686 \mathrm{X}-4.4333 \mathrm{R}^{2}=0.9801$ & $3.26 \pm 0.02^{\mathrm{b}}$ \\
\hline \multirow{2}{*}{ Hydroxyl free radical } & 30-FSDC & $\mathrm{Y}=8.96 \mathrm{X}-2.1133 \mathrm{R}^{2}=0.9953$ & $5.82 \pm 0.03^{\mathrm{a}}$ \\
scavenging capacity & 35-FSDC & $\mathrm{Y}=13.417 \mathrm{X}-0.28 \mathrm{R}^{2}=0.9869$ & $3.75 \pm 0.02^{\mathrm{c}}$ \\
& 40-FSDC & $\mathrm{Y}=11.806 \mathrm{X}-2.26 \mathrm{R}^{2}=0.9983$ & $4.43 \pm 0.03^{\mathrm{b}}$ \\
\hline
\end{tabular}

Values represent the the mean \pm standard deviation. ${ }^{\mathrm{a}-\mathrm{c}}$ Mean values with different letters in the same row are significantly different $(p<0.05)$. 30-FSDC: $30^{\circ} \mathrm{C}$ fermented Shuidouchi; 35-FSDC: $35^{\circ} \mathrm{C}$ fermented Shuidouchi; 40-FSDC: $40^{\circ} \mathrm{C}$ fermented Shuidouchi.

\subsection{Comparison of Soybean Isoflavone Contents of Shuidouchi Fermented for Different Durations}

The soybean isoflavone contents of Shuidouchi fermented for 24,48 , and $72 \mathrm{~h}$ were $35.67,58.87$, and $48.51 \mathrm{mg} / \mathrm{g}$, respectively (Figure 5). The soybean isoflavone content of unfermented soybean was $33.71 \mathrm{mg} / \mathrm{g}$. 


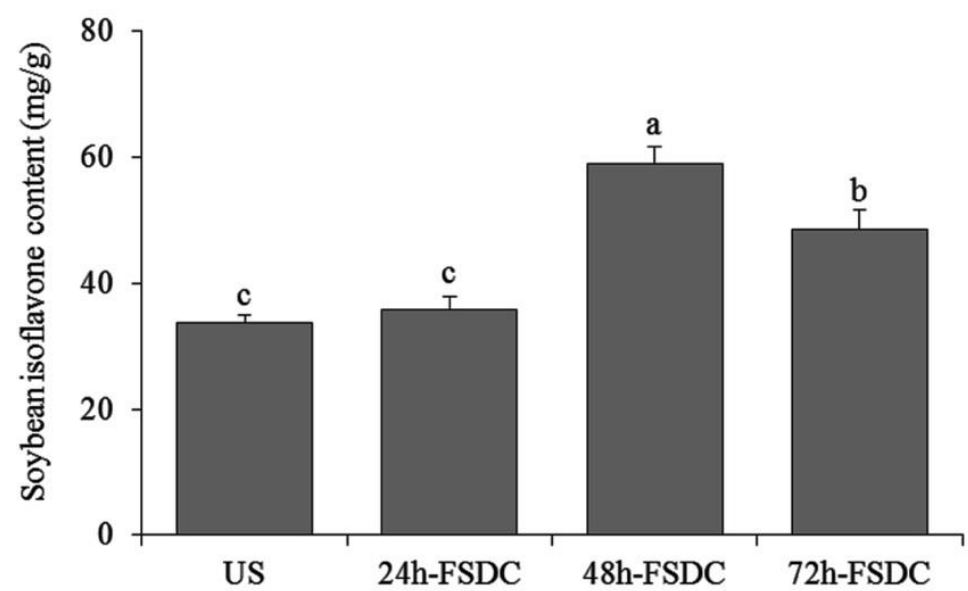

Figure 5. Soybean isoflavone contents on Shuidouchi fermented at different times. ${ }^{\mathrm{a}-\mathrm{c}}$ Mean values with different letters in the bar indicate significant differences $(p<0.05)$. US: unfermented soybean; 24h-FSDC: $24 \mathrm{~h}$ fermented Shuidouchi; 48h-FSDC: $48 \mathrm{~h}$ fermented Shuidouchi; 72h-FSDC: $72 \mathrm{~h}$ fermented Shuidouchi.

\subsection{Comparison of Antioxidant Effects of Shuidouchi Fermented for Different Durations}

The results in Figure 6 and Table 7 indicate that fermentation duration influences the antioxidant effects of Shuidouchi under otherwise identical conditions. The DPPH, $\mathrm{ABTS}^{+}$, and hydroxyl radical scavenging rates of Shuidouchi fermented for 24,48 , and $72 \mathrm{~h}$ were significantly different. The DPPH, $\mathrm{ABTS}^{+}$, and hydroxyl radicals scavenging rates of Shuidouchi extract that was fermented for $48 \mathrm{~h}$ were higher than those of Shuidouchi extract fermented for 24 and $72 \mathrm{~h}$.

(A)

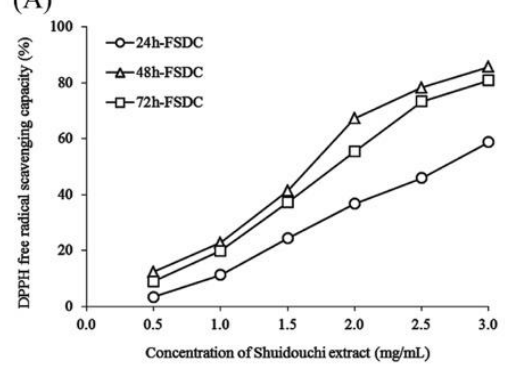

(B)

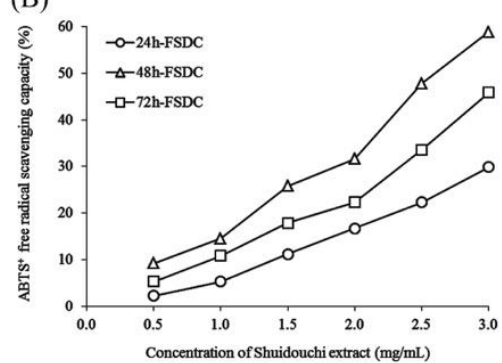

(C)

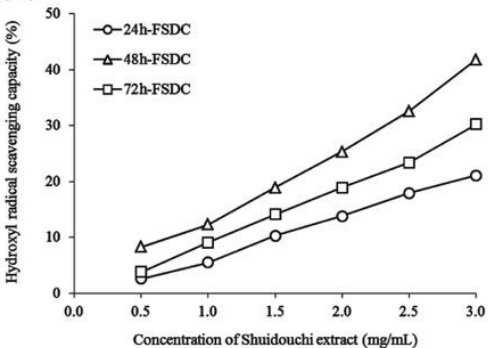

Figure 6. DPPH (A), $\mathrm{ABTS}^{+}(\mathbf{B})$, and hydroxyl (C) free radical scavenging capacity of Shuidouchi with different fermentation durations. 24h-FSDC: $24 \mathrm{~h}$ fermented Shuidouchi; $48 \mathrm{~h}-F S D C: 48 \mathrm{~h}$ fermented Shuidouchi; 72h-FSDC: $72 \mathrm{~h}$ fermented Shuidouchi.

Table 7. DPPH (A), $\mathrm{ABTS}^{+}$(B), and hydroxyl (C) free radical scavenging capacities of Shuidouchi extract fermented for different durations.

\begin{tabular}{clll}
\hline Type & Group & Linear Regression Equation & IC $_{50}(\mathrm{mg} / \mathrm{mL})$ \\
\hline \multirow{2}{*}{ DPPH free radical } & 24h-FSDC & $\mathrm{Y}=22.486 \mathrm{X}-9.3333 \mathrm{R}^{2}=0.9996$ & $2.64 \pm 0.01^{\mathrm{a}}$ \\
scavenging capacity & $48 \mathrm{~h}-\mathrm{FSDC}$ & $\mathrm{Y}=31.937 \mathrm{X}-4.64 \mathrm{R}^{2}=0.9719$ & $1.71 \pm 0.03^{\mathrm{c}}$ \\
& 72h-FSDC & $\mathrm{Y}=30.749 \mathrm{X}-7.9267 \mathrm{R}^{2}=0.9889$ & $1.88 \pm 0.03^{\mathrm{b}}$ \\
\hline \multirow{2}{*}{ ABTS $^{+}$free radical } & 24h-FSDC & $\mathrm{Y}=11.143 \mathrm{X}-4.9 \mathrm{R}^{2}=0.9884$ & $4.93 \pm 0.02^{\mathrm{a}}$ \\
scavenging capacity $^{\mathrm{c}}$ & $48 \mathrm{~h}-\mathrm{FSDC}$ & $\mathrm{Y}=20.24 \mathrm{X}-4.12 \mathrm{R}^{2}=0.9767$ & $2.67 \pm 0.03^{\mathrm{c}}$ \\
& 72h-FSDC & $\mathrm{Y}=15.76 \mathrm{X}-4.9467 \mathrm{R}^{2}=0.9663$ & $3.49 \pm 0.02^{\mathrm{b}}$ \\
\hline \multirow{2}{*}{ Hydroxyl free radical } & 24h-FSDC & $\mathrm{Y}=7.6114 \mathrm{X}-1.4533 \mathrm{R}^{2}=0.9969$ & $6.76 \pm 0.02^{\mathrm{a}}$ \\
scavenging capacity & 48h-FSDC & $\mathrm{Y}=13.417 \mathrm{X}-0.28 \mathrm{R}^{2}=0.9869$ & $3.75 \pm 0.03^{\mathrm{c}}$ \\
& 72h-FSDC & $\mathrm{Y}=10.269 \mathrm{X}-1.3867 \mathrm{R}^{2}=0.9967$ & $5.00 \pm 0.02^{\mathrm{b}}$ \\
\hline
\end{tabular}

Values presented are the mean \pm standard deviation. ${ }^{\mathrm{a}-\mathrm{c}}$ Mean values with different letters in the same row are significantly different $(p<0.05)$. 24h-FSDC: $24 \mathrm{~h}$ fermented Shuidouchi; $48 \mathrm{~h}-F S D C: 48 \mathrm{~h}$ fermented Shuidouchi; 72h-FSDC: $72 \mathrm{~h}$ fermented Shuidouchi. 


\subsection{Comparison of Soybean Isoflavone Contents of Shuidouchi Soaked in Different Water Quantities}

The soybean isoflavone contents in fermented Shuidouchi extract that was soaked in different quantities of water were $40.35,58.87$, and $56.37 \mathrm{mg} / \mathrm{g}$ (genistein meter), respectively. Unfermented soybeans contained $33.71 \mathrm{mg} / \mathrm{g}$ soybean isoflavone, which was in accordance with the standard curve for genistein, $\mathrm{Y}=0.1709 \mathrm{X}+0.0095$ (Figure 7).

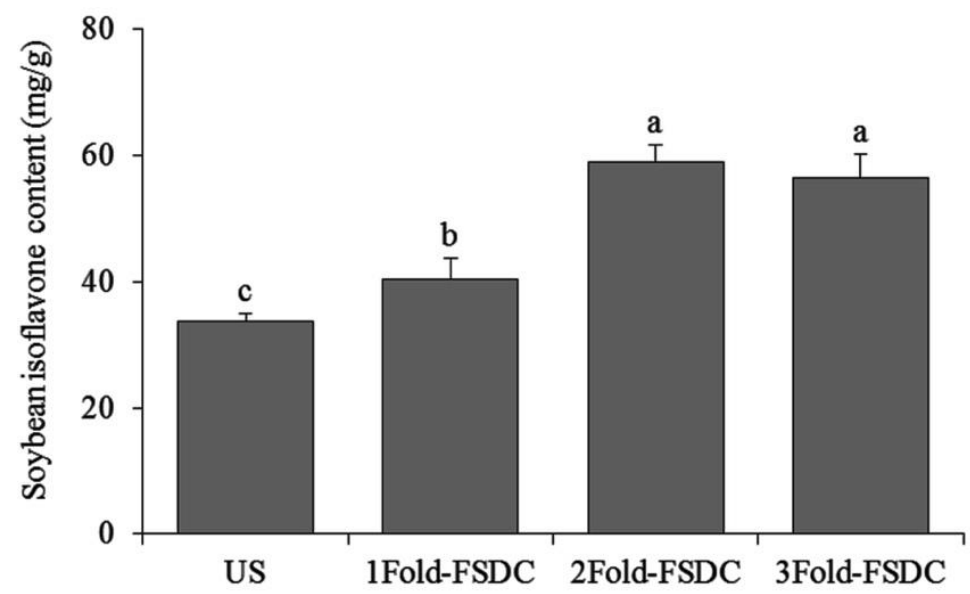

Figure 7. Soybean isoflavone contents of Shuidouchi soaked in different water volumes. ${ }^{\mathrm{a}-\mathrm{c}}$ Mean values with different letters in the bar are significantly different $(p<0.05)$. US: unfermented soybean; 1Fold-FSDC: 1-fold soaking water of soybeans for Shuidouchi fermentation; 2Fold-FSDC: 2-fold soaking water of soybeans for Shuidouchi fermentation; 3Fold-FSDC: 3-fold soaking water of soybeans for Shuidouchi fermentation.

\subsection{Comparison of Antioxidant Effects of Shuidouchi in Different Quantities of Soaking Water}

The results that are shown in Figure 8 and Table 8 indicate that the quantity of soaking water affects the antioxidant effects of Shuidouchi extract. The extracts soaked in two and three times more water exerted enhanced antioxidant effects, with the former exhibiting slightly better antioxidant effects than the latter.
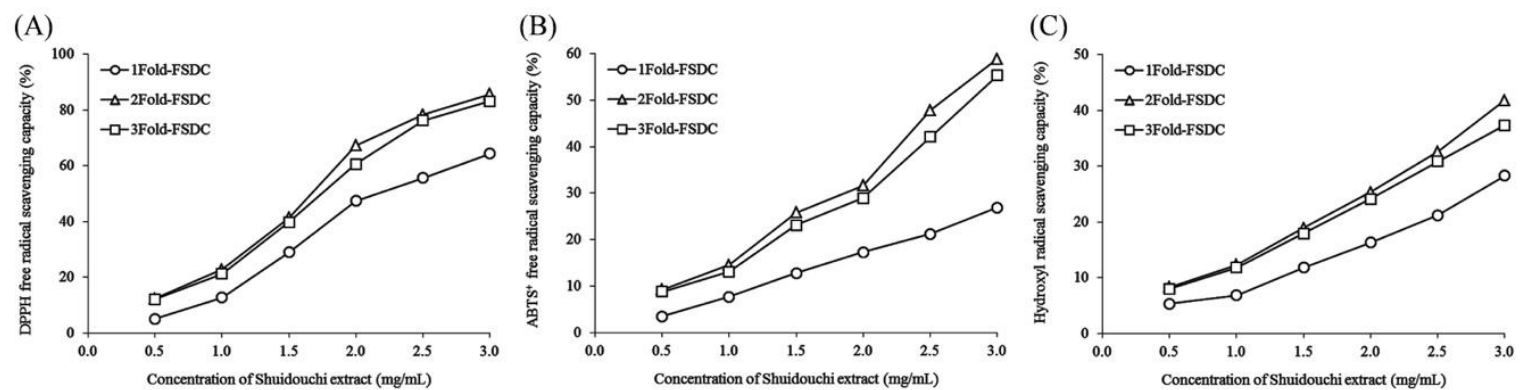

Figure 8. DPPH (A), $\mathrm{ABTS}^{+}(\mathbf{B})$, and hydroxyl (C) free radical scavenging capacity of Shuidouchi at different soaking water levels. 1Fold-FSDC: 1-fold soaking water of soybeans for Shuidouchi fermentation; 2Fold-FSDC: 2-fold soaking water of soybeans for Shuidouchi fermentation; 3Fold-FSDC: 3-fold soaking water of soybeans for Shuidouchi fermentation. 
Table 8. DPPH (A), $\mathrm{ABTS}^{+}$(B), and hydroxyl (C) free radical scavenging capacity of Shuidouchi soaked in different amounts of water.

\begin{tabular}{cccc}
\hline Type & Group & Linear Regression Equation & IC $_{50}(\mathbf{m g} / \mathbf{m L})$ \\
\hline \multirow{2}{*}{ DPPH free radical } & 1Fold-FSDC & $\mathrm{Y}=25.32 \mathrm{X}-98.66 \mathrm{R}^{2}=0.9807$ & $2.32 \pm 0.02^{\mathrm{a}}$ \\
scavenging capacity & 2Fold-FSDC & $\mathrm{Y}=31.937 \mathrm{X}-94.64 \mathrm{R}^{2}=0.9719$ & $1.71 \pm 0.02^{\mathrm{c}}$ \\
& 3Fold-FSDC & $\mathrm{Y}=30.909 \mathrm{X}-95.2733 \mathrm{R}^{2}=0.9816$ & $1.79 \pm 0.02^{\mathrm{b}}$ \\
\hline \multirow{2}{*}{ ABTS $^{+}$free radical } & 1Fold-FSDC & $\mathrm{Y}=9.2571 \mathrm{X}-91.3 \mathrm{R}^{2}=0.998$ & $5.54 \pm 0.01^{\mathrm{a}}$ \\
scavenging capacity $^{\mathrm{C}}$ & 2Fold-FSDC & $\mathrm{Y}=20.24 \mathrm{X}-94.12 \mathrm{R}^{2}=0.9767$ & $2.67 \pm 0.02^{\mathrm{c}}$ \\
& 3Fold-FSDC & $\mathrm{Y}=18.589 \mathrm{X}-93.98 \mathrm{R}^{2}=0.9704$ & $2.90 \pm 0.03^{\mathrm{b}}$ \\
\hline \multirow{2}{*}{ Hydroxyl free radical } & 1Fold-FSDC & $\mathrm{Y}=9.2971 \mathrm{X}-91.32 \mathrm{R}^{2}=0.9732$ & $5.52 \pm 0.03^{\mathrm{a}}$ \\
scavenging capacity & 2Fold-FSDC & $\mathrm{Y}=13.417 \mathrm{X}-90.28 \mathrm{R}^{2}=0.9869$ & $3.75 \pm 0.02^{\mathrm{c}}$ \\
& 3Fold-FSDC & $\mathrm{Y}=11.983 \mathrm{X}+0.68 \mathrm{R}^{2}=0.9939$ & $4.23 \pm 0.03^{\mathrm{b}}$ \\
\hline
\end{tabular}

Values present the mean \pm standard deviation. ${ }^{\mathrm{a}-\mathrm{c}}$ Mean values with different letters in the same row are significantly different $(p<0.05)$. 1Fold-FSDC: 1-fold soaking water for Shuidouchi fermentation; 2Fold-FSDC: 2-fold soaking water for Shuidouchi fermentation; 3Fold-FSDC: 3-fold soaking water for Shuidouchi fermentation.

\subsection{Comparison of Soybean Isoflavone Contents on Shuidouchi Fermented in Different Containers}

In accordance with the standard curve $\mathrm{Y}=0.1709 \mathrm{X}+0.0095$ for genistein, the soybean isoflavone content of unfermented soybean was $33.71 \mathrm{mg} / \mathrm{g}$; furthermore, the soybean isoflavone contents in the Shuidouchi extract fermented in ceramic, glass, and metal containers were $47.74,58.87$, and $44.12 \mathrm{mg} / \mathrm{g}$, respectively (Figure 9).

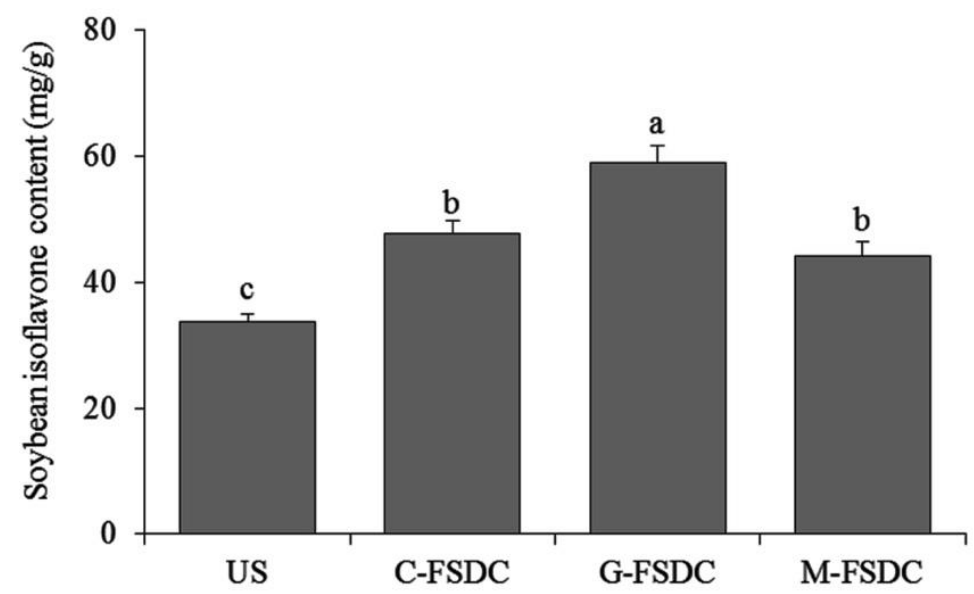

Figure 9. Soybean isoflavone contents of Shuidouchi fermented in different containers. ${ }^{\mathrm{a}-\mathrm{c}}$ Mean values with different letters in the bar are significantly different $(p<0.05)$. US: unfermented soybean; C-FSDC: Ceramic container used for Shuidouchi fermentation; G-FSDC: Glass container used for Shuidouchi fermentation; M-FSDC: Metal container used for Shuidouchi fermentation.

\subsection{Comparison of Antioxidant Effects of Shuidouchi Fermented in Different Containers}

The results that are shown in Figure 10 and Table 9 show that, under otherwise identical fermentation conditions, the fermentation container affects Shuidouchi fermentation. The antioxidant effect of Shuidouchi fermented in the glass container exceeded that of Shuidouchi that was fermented in ceramic and metal containers. 

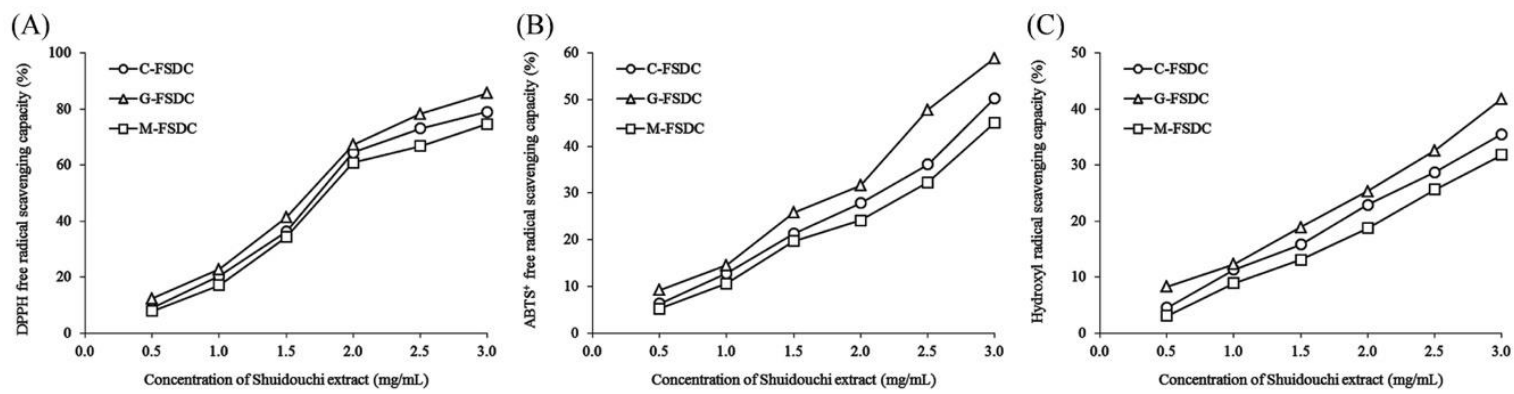

Figure 10. DPPH (A), $\mathrm{ABTS}^{+}(\mathbf{B})$, and hydroxyl (C) free radical scavenging capacity of Shuidouchi fermented in different containers. C-FSDC: Ceramic container used for Shuidouchi fermentation; G-FSDC: Glass container used for Shuidouchi fermentation; M-FSDC: Metal container used for Shuidouchi fermentation.

Table 9. DPPH (A), $\mathrm{ABTS}^{+}(\mathrm{B})$, and hydroxyl (C) free radical scavenging capacity of Shuidouchi fermentated in different containers.

\begin{tabular}{cccc}
\hline Type & Group & Linear Regression Equation & IC $_{50}(\mathbf{m g} / \mathbf{m L})$ \\
\hline \multirow{2}{*}{ DPPH free radical } & C-FSDC & $\mathrm{Y}=30.697 \mathrm{X}-6.72 \mathrm{R}^{2}=0.9604$ & $1.85 \pm 0.02^{\mathrm{a}}$ \\
scavenging capacity & G-FSDC & $\mathrm{Y}=31.937 \mathrm{X}-4.64 \mathrm{R}^{2}=0.9719$ & $1.71 \pm 0.03^{\mathrm{c}}$ \\
& $\mathrm{M}-F S D C$ & $\mathrm{Y}=29.074 \mathrm{X}-7.3133 \mathrm{R}^{2}=0.9597$ & $1.97 \pm 0.02^{\mathrm{b}}$ \\
\hline \multirow{2}{*}{ ABTS $^{+}$free radical } & C-FSDC & $\mathrm{Y}=16.937 \mathrm{X}-3.8733 \mathrm{R}^{2}=0.9806$ & $3.18 \pm 0.02^{\mathrm{a}}$ \\
scavenging capacity $^{\mathrm{c}}$ & G-FSDC & $\mathrm{Y}=20.24 \mathrm{X}-4.12 \mathrm{R}^{2}=0.9767$ & $2.67 \pm 0.02^{\mathrm{c}}$ \\
& $\mathrm{M}-F S D C$ & $\mathrm{Y}=15.371 \mathrm{X}-4.0667 \mathrm{R}^{2}=0.9776$ & $3.52 \pm 0.03^{\mathrm{b}}$ \\
\hline \multirow{2}{*}{ Hydroxyl free radical } & C-FSDC & $\mathrm{Y}=12.246 \mathrm{X}-1.6467 \mathrm{R}^{2}=0.9976$ & $4.22 \pm 0.02^{\mathrm{a}}$ \\
scavenging capacity & G-FSDC & $\mathrm{Y}=13.417 \mathrm{X}-0.28 \mathrm{R}^{2}=0.9869$ & $3.75 \pm 0.02^{\mathrm{c}}$ \\
& $\mathrm{M}-F S D C$ & $\mathrm{Y}=11.383 \mathrm{X}-3.0533 \mathrm{R}^{2}=0.9948$ & $4.66 \pm 0.02^{\mathrm{b}}$ \\
\hline
\end{tabular}

Values represent the mean \pm standard deviation. ${ }^{a-c}$ Mean values with different letters in the same row are significantly different $(p<0.05)$. C-FSDC: Ceramic container used for Shuidouchi fermentation; G-FSDC: Glass container used for Shuidouchi fermentation; M-FSDC: Metal container used for Shuidouchi fermentation.

Due to the different materials of fermentation containers, the temperature and water content of fermentation products can differ, thus resulting in different growth of fermentation microorganisms, which in turn affects the fermentation products [19]. After analyzing various fermentation factors, it was found that Shuidouchi fermented under specific condition (twice as much soaking water in glass container at $35^{\circ} \mathrm{C}$ for $48 \mathrm{~h}$ ) contained the most soybean isoflavones. This particular fermented Shuidouchi showed the highest DPPH, ABTS+, and hydroxyl radical scavenging capacities of all the different tested conditions. These results indicate that soybean isoflavone is an important active component that is produced by the antioxidant effect of Shuidouchi and exhibits a direct relationship with the antioxidant effect.

\subsection{Effects of Shuidouchi on Colonic Length and Weight of Mice with Colitis}

The results showed that the normal group had the longest colon but the least colon weight-to-colon length ratio (Table 10). The results that were obtained for the control group were opposite to those obtained for the normal group. The control group showed the shortest colon length and the largest colon weight-to-colon length ratio. The colon length and the colon weight-to-colon length ratio of the SDC-H group were closest to those of the normal group. The colon of the SDC-H group was only slightly shorter than those of both the normal group and the sulfasalazine group and longer than those of the control group and the SDC-L group. Furthermore, the colon weight-to-colon length ratio of the SDC-H group was higher than those of the normal group and the sulfasalazine group and lower than those of the control group and the SDC-L group. 
Table 10. Colon lengths and colon weight-to-colon length ratios.

\begin{tabular}{ccc}
\hline Group. & Colon Lengths $\mathbf{( c m )}$ & Colon Weight-to-Colon Length Ratios $(\mathbf{m g} / \mathbf{c m})$ \\
\hline Normal & $9.3 \pm 0.3^{\mathrm{a}}$ & $22.1 \pm 1.8^{\mathrm{a}}$ \\
Control & $4.1 \pm 0.4^{\mathrm{e}}$ & $43.8 \pm 2.2^{\mathrm{e}}$ \\
SDC-L & $5.6 \pm 0.4^{\mathrm{d}}$ & $38.6 \pm 1.6^{\mathrm{d}}$ \\
SDC-H & $7.1 \pm 0.3^{\mathrm{c}}$ & $34.2^{\mathrm{c}} \pm 1.2^{\mathrm{c}}$ \\
Sulfasalazine & $7.8 \pm 0.3^{\mathrm{b}}$ & $29.7 \pm 1.4^{\mathrm{b}}$ \\
\hline
\end{tabular}

Values represent the mean \pm standard deviation. ${ }^{\text {a-e }}$ Mean values with different letters in the same row indicate significant difference $(p<0.05)$. SDC-L: $2 \mathrm{~g} / \mathrm{kg}$ Shuidouchi extract treatment; SDC-H: $4 \mathrm{~g} / \mathrm{kg}$ Shuidouchi extract treatment; Sulfasalazine: $20 \mathrm{mg} / \mathrm{kg}$ sulfasalazine treatment.

\subsection{Effects of Shuidouchi on Disease Activity Index of Mice with Colitis}

The results showed that the DAI index of the control group was higher than that of the other groups during the experimental period and that the DAI indices of the mice in all groups, except for the normal group, increased significantly after treatment with DSS at Weeks 3 (2.32) and 5 (3.62) (Figure 11). On the 35th day, the SDC-L (2.68), SDC-H (1.89), and sulfasalazine (1.52) groups showed significant inhibitions of the increase in the DAI index in mice with colitis, with sulfasalazine exhibiting the highest inhibition, followed by SDC-H, and then SDC-L. Therefore, the improved Shuidouchi extract fermentation process could inhibit the increase of DAI index in mice with colitis.

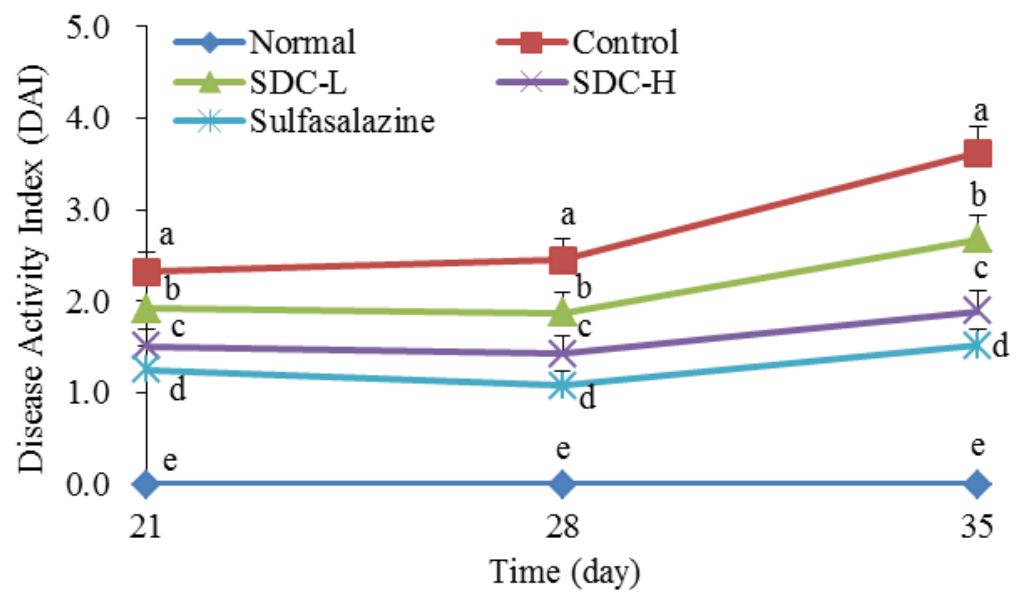

Figure 11. Disease activity index of mice with colitis. ${ }^{\text {a-e }}$ Mean values with different letters in the same day indicate significant difference $(p<0.05)$. SDC-L: $2 \mathrm{~g} / \mathrm{kg}$ Shuidouchi extract treatment; SDC-H: $4 \mathrm{~g} / \mathrm{kg}$ Shuidouchi extract treatment; Sulfasalazine: $20 \mathrm{mg} / \mathrm{kg}$ sulfasalazine treatment.

\subsection{Effects of Shuidouchi on Serum Levels of Et, Ss, Sp, And Vip in Mice with Colitis}

The results in Table 11 show that the ET and SP serum levels of the normal group are the lowest, while the SS and VIP serum levels are the highest; the ET and SP serum levels of the control group are the highest, while the SS and VIP levels are the lowest. The SDC-L, SDC-H, and sulfasalazine groups could significantly decrease the ET and SP levels and increase the SS and VIP levels in mice with colitis. Sulfasalazine exerted the strongest effect, followed by high concentration of Shuidouchi, and then low concentration of Shuidouchi. 
Table 11. Endothelin (ET), somatostatin (SS), substance P (SP), and vasoactive intestinal peptide (VIP) serum levels in mice.

\begin{tabular}{ccccc}
\hline Group. & ET $(\mathbf{p g} / \mathbf{m L})$ & SS $(\mathbf{p g} / \mathbf{m L})$ & SP $(\mathbf{p g} / \mathbf{m L})$ & VIP $(\mathbf{p g} / \mathbf{m L})$ \\
\hline Normal & $6.12 \pm 0.16^{\mathrm{e}}$ & $59.87 \pm 2.97^{\mathrm{a}}$ & $38.14 \pm 1.56^{\mathrm{e}}$ & $66.61 \pm 2.42^{\mathrm{a}}$ \\
Control & $23.08 \pm 0.39^{\mathrm{a}}$ & $23.54 \pm 2.02^{\mathrm{e}}$ & $63.41 \pm 2.18^{\mathrm{a}}$ & $29.36 \pm 2.11^{\mathrm{e}}$ \\
SDC-L & $17.76 \pm 0.31^{\mathrm{b}}$ & $31.02 \pm 2.12^{\mathrm{d}}$ & $53.10 \pm 2.06^{\mathrm{b}}$ & $38.71 \pm 1.69^{\mathrm{d}}$ \\
SDC-H & $11.62 \pm 0.25^{\mathrm{c}}$ & $42.58 \pm 2.51^{\mathrm{c}}$ & $46.02 \pm 1.62^{\mathrm{c}}$ & $46.31 \pm 2.11^{\mathrm{c}}$ \\
Sulfasalazine & $9.47 \pm 0.19^{\mathrm{d}}$ & $49.71 \pm 2.37^{\mathrm{b}}$ & $42.31 \pm 1.55^{\mathrm{d}}$ & $52.36 \pm 2.01^{\mathrm{b}}$ \\
\hline
\end{tabular}

Values represent the mean \pm standard deviation. ${ }^{\text {a-e }}$ Mean values with different letters in the same row indicate significant difference $(p<0.05)$. SDC-L: $2 \mathrm{~g} / \mathrm{kg}$ Shuidouchi extract treatment; SDC-H: $4 \mathrm{~g} / \mathrm{kg}$ Shuidouchi extract treatment; sulfasalazine: $20 \mathrm{mg} / \mathrm{kg}$ sulfasalazine treatment. ET: endothelin; SS: somatostatin; SP: substance P; VIP: vasoactive intestinal peptide.

\subsection{Effects of Shuidouchi on Serum Levels of Il-2 and Il-10 Cytokines in Mice With Colitis}

The results in Table 12 show that the IL-2 levels are lowest in all groups, and the IL-10 in the control group is the highest; the sulfasalazine, SDC-H, and SDC-L groups show significant increases of IL-2 levels and decreased IL-10 levels. Due to sulfasalazine, SDC-H, and SDC-L, the IL-2 and IL-10 cytokine levels in the sulfasalazine group were the closest to those in the normal group. The IL-2 and IL-10 levels in the SDC-H group were similar to those in the normal group, which significantly improved the IL-2 and IL-10 serum cytokine levels in mice with colon cancer.

Table 12. Serum cytokine levels of interleukin-2 (IL-2) and interleukin-10 (IL-10) in mice.

\begin{tabular}{ccc}
\hline Group & IL-2 $(\mathbf{p g} / \mathbf{m L})$ & IL-10 $(\mathbf{p g} / \mathbf{m L})$ \\
\hline Normal & $248.20 \pm 32.39^{\mathrm{a}}$ & $133.56 \pm 15.51^{\mathrm{e}}$ \\
Control & $70.82 \pm 12.36^{\mathrm{d}}$ & $763.52 \pm 25.39^{\mathrm{a}}$ \\
SDC-L & $95.63 \pm 17.82^{\mathrm{c}}$ & $541.02 \pm 22.58^{\mathrm{b}}$ \\
SDC-H & $155.88 \pm 20.84^{\mathrm{bc}}$ & $352.36 \pm 20.02^{\mathrm{c}}$ \\
Sulfasalazine & $192.76 \pm 22.33^{\mathrm{b}}$ & $234.19 \pm 24.48^{\mathrm{d}}$ \\
\hline
\end{tabular}

Values represent the mean \pm standard deviation. ${ }^{a-e}$ Mean values with different letters in the same row indicate significant difference $(p<0.05)$. SDC-L: $2 \mathrm{~g} / \mathrm{kg}$ Shuidouchi extract treatment; SDC-H: $4 \mathrm{~g} / \mathrm{kg}$ Shuidouchi extract treatment; Sulfasalazine: $20 \mathrm{mg} / \mathrm{kg}$ sulfasalazine treatment. IL-2: interleukin-2; IL-10: interleukin-10.

3.13. Effects of Shuidouchi on the Myeloperoxidase, Superoxide Dismutase, Glutathione, and Malondialdehyde Levels in the Colon Tissue of Mice With Colitis

The results in Table 13 show that the normal group exhibits the highest GSH and SOD levels, but the lowest MPO and MDA levels. After colitis induction, the GSH and SOD levels decreased, while the MPO and MDA levels increased in DSS-induced mice. Significant inhibition of decreases in GSH and SOD and increases in MPO and MDA levels caused by colitis were found in the sulfasalazine, SDC-H, and SDC-L groups. Sulfasalazine showed the strongest inhibitory action, followed by SDC-H and SDC-L. 
Table 13. Myeloperoxidase (MPO), superoxide dismutase (SOD), glutathione (GSH), and malondialdehyde (MDA) levels in colon tissues of mice.

\begin{tabular}{ccccc}
\hline Group & MPO (mU/mg) & GSH $(\mu \mathbf{m o l} / \mathbf{m g})$ & MDA (nmol/mg) & SOD (U/mg) \\
\hline Normal & $6.35 \pm 0.25^{\mathrm{e}}$ & $8.33 \pm 0.35^{\mathrm{a}}$ & $0.30 \pm 0.06^{\mathrm{d}}$ & $93.74 \pm 4.21^{\mathrm{a}}$ \\
Control & $33.87 \pm 2.68^{\mathrm{a}}$ & $3.10 \pm 0.22^{\mathrm{e}}$ & $1.77 \pm 0.23^{\mathrm{a}}$ & $28.30 \pm 3.03^{\mathrm{e}}$ \\
SDC-L & $25.31 \pm 1.77^{\mathrm{b}}$ & $4.52 \pm 0.25^{\mathrm{d}}$ & $1.18 \pm 0.12^{\mathrm{b}}$ & $44.25 \pm 2.62^{\mathrm{d}}$ \\
SDC-H & $12.30 \pm 1.52^{\mathrm{c}}$ & $5.89 \pm 0.21^{\mathrm{c}}$ & $0.78 \pm 0.14^{\mathrm{c}}$ & $67.12 \pm 2.88^{\mathrm{c}}$ \\
Sulfasalazine & $9.01 \pm 1.28^{\mathrm{d}}$ & $6.38 \pm 0.20^{\mathrm{b}}$ & $0.55 \pm 0.15^{\mathrm{c}}$ & $80.35 \pm 2.39^{\mathrm{b}}$ \\
\hline
\end{tabular}

Values represent the mean \pm standard deviation. ${ }^{\text {a-e }}$ Mean values with different letters in the same row indicate significant difference $(p<0.05)$. SDC-L: $2 \mathrm{~g} / \mathrm{kg}$ Shuidouchi extract treatment; SDC-H: $4 \mathrm{~g} / \mathrm{kg}$ Shuidouchi extract treatment; Sulfasalazine: $20 \mathrm{mg} / \mathrm{kg}$ sulfasalazine treatment. MPO: myeloperoxidase; GSH: glutathione; MDA: malondialdehyde; SOD: superoxide dismutase.

\subsection{Effects of Shuidouchi on Expression of Nnos, Enos, and Inos Mrna in Colon Tissues of Mice with Colitis}

The results showed that the expression of nNOS mRNA in the colon tissue of the normal group was 4.36 times that of mice in the control group, and the expression levels of nNOS in the colon tissues in the SDC-H, SDC-L, and SDC-H groups were 3.23, 2.79, and 1.87 times that of the control group, respectively (Figure 12). The colon tissues in the normal group exhibited the highest eNOS expression (3.79 times of that in the control group); eNOS expression in the sulfasalazine group was only 3.01 times that in the normal group (3.01 times that in the control group); and, eNOS expression in the SDC-H group (2.62 times that in the control group) was higher than that in the SDC-L group. (1.92 times in the control group). In contrast, the colon tissues of the normal group showed the lowest iNOS mRNA expression, which was only 0.25 times that of the control group. After treatment with sulfasalazine, high Shuidoichi concentration, and low Shuidoichi concentration, the expressions of iNOS mRNA in the colon of mice with colitis decreased to $0.41,0.52$, and 0.79 , respectively, of that of the control group.

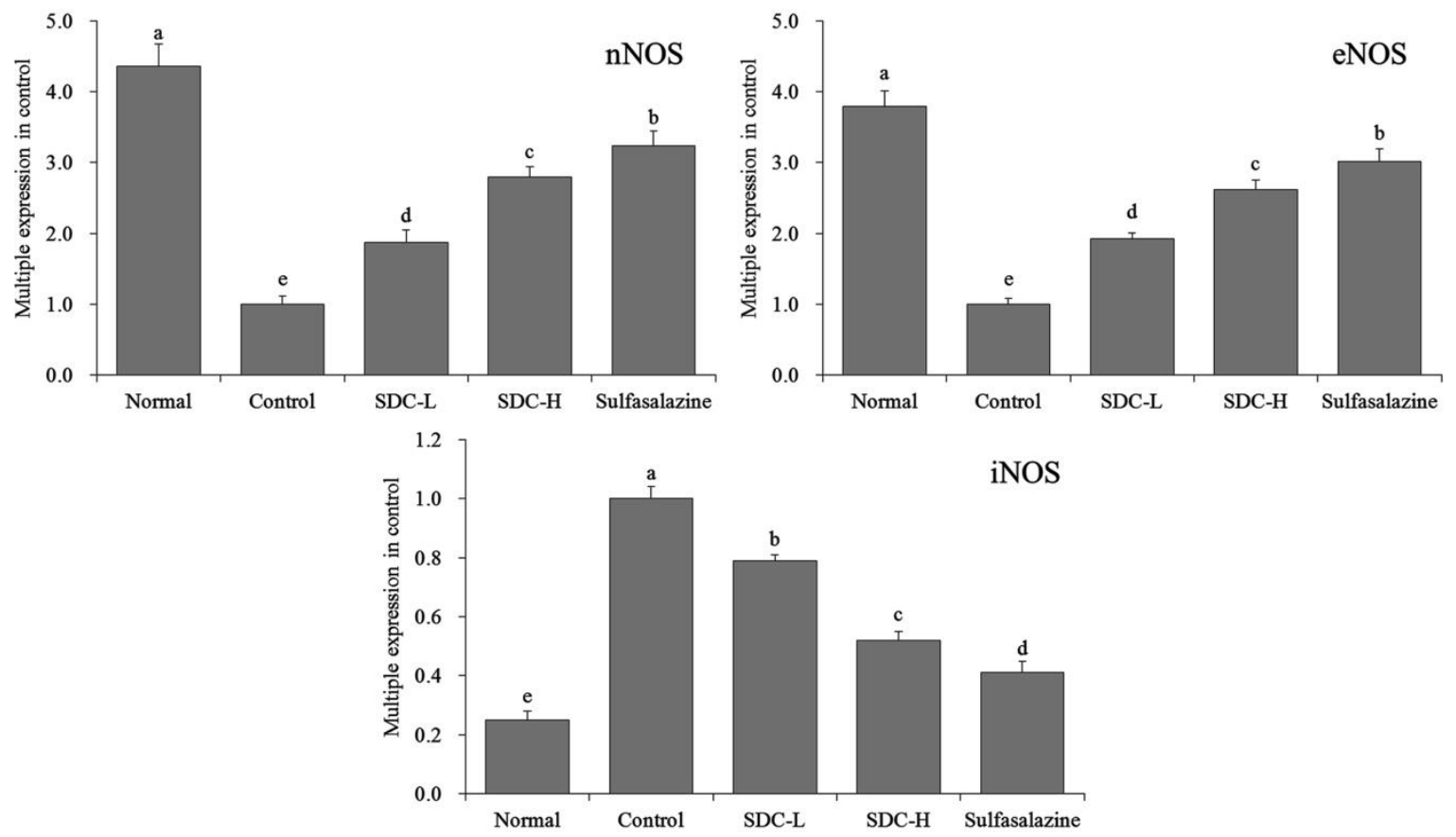

Figure 12. mRNA expression levels of neuronal nitric oxide synthase (nNOS), endothelial nitric oxide synthase (eNOS), and inducible nitric oxide synthase (iNOS) in the colon tissue of mice. Values represent the mean \pm standard deviation. ${ }^{\text {a-e }}$ Mean values with different letters in the same bars indicate significant difference ( $p<0.05)$. SDC-L: $2 \mathrm{~g} / \mathrm{kg}$ Shuidouchi extract treatment; SDC-H: $4 \mathrm{~g} / \mathrm{kg}$ Shuidouchi extract treatment; Sulfasalazine: $20 \mathrm{mg} / \mathrm{kg}$ sulfasalazine treatment. 


\subsection{Effects of Shuidouchi on Expression of c-Kit and SCF mRNA in Colon Tissues of Mice with Colitis}

The results in Figure 13 show that the expression of c-Kit mRNA in the colon of the normal group (6.38 times of that of the control mice) was significantly higher than that in the other groups. The expression of c-Kit mRNA in the colon of the sulfasalazine group (5.52 times of that of the control mice) and SDC-H group mice (4.8 times of that of the control mice) was also higher than that of the SDC-L group (2.71 times of that of the control group). Simultaneously, the expression levels of SCF mRNA in the colon tissues of the normal group, sulfasalazine group, SDC-H group, and SDC-L group were $5.33,4.89,4.36$, and 2.21 of that of the control group, respectively.
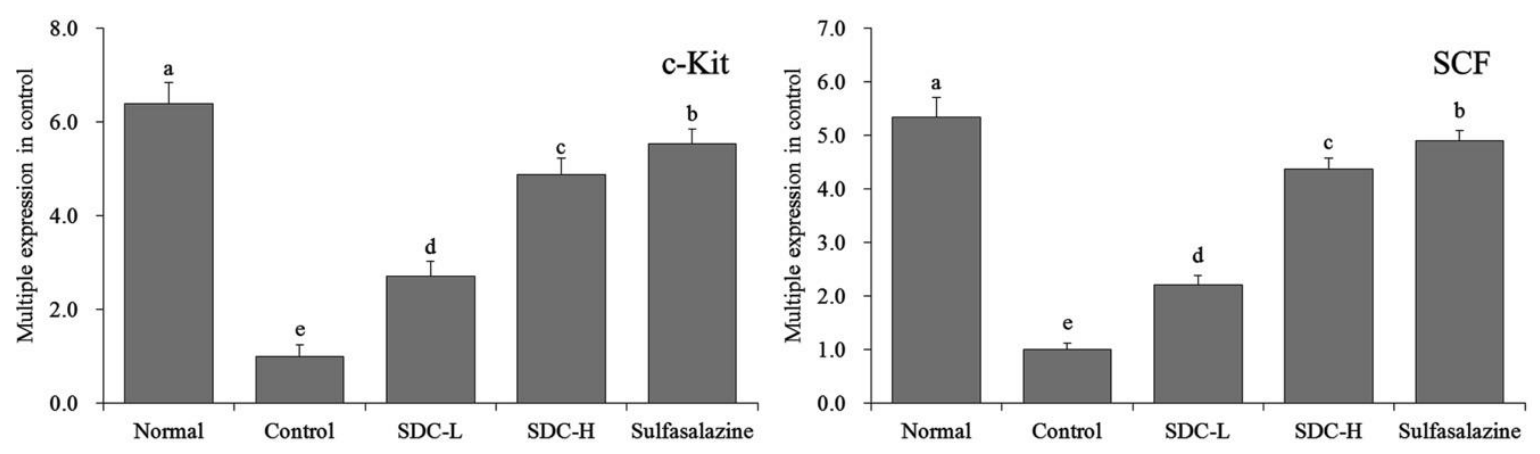

Figure 13. mRNA expression levels of $\mathrm{c}-\mathrm{Kit}$ and SCF in colon tissues of mice. Values represent the mean \pm standard deviation. ${ }^{\text {a-e }}$ Mean values with different letters in the same bars indicate significant difference $(p<0.05)$. SDC-L: $2 \mathrm{~g} / \mathrm{kg}$ Shuidouchi extract treatment; SDC-H: $4 \mathrm{~g} / \mathrm{kg}$ Shuidouchi extract treatment; Sulfasalazine: $20 \mathrm{mg} / \mathrm{kg}$ sulfasalazine treatment.

3.16. Effects of Shuidouchi on Expression Levels of IL-8 and CXCR2 Mrna in Colon Tissues of Mice with Colitis

The IL-8 mRNA expression in the colonic tissue of mice of the normal group was 0.14 times that of the control group, which was weaker than that of the sulfasalazine group (0.22 times of that of the control group), SDC-H group (0.38 times of that of the control group), and SDC-L group (0.69 times of that of the control group; Figure 14). The control group exhibited the highest CXCR2 mRNA expression. The CXCR2 expression levels in the normal group, sulfasalazine group, SDC-H group, and SDC-L group were $0.19,0.35,0.44$, and 0.65 times higher than that of the control group.
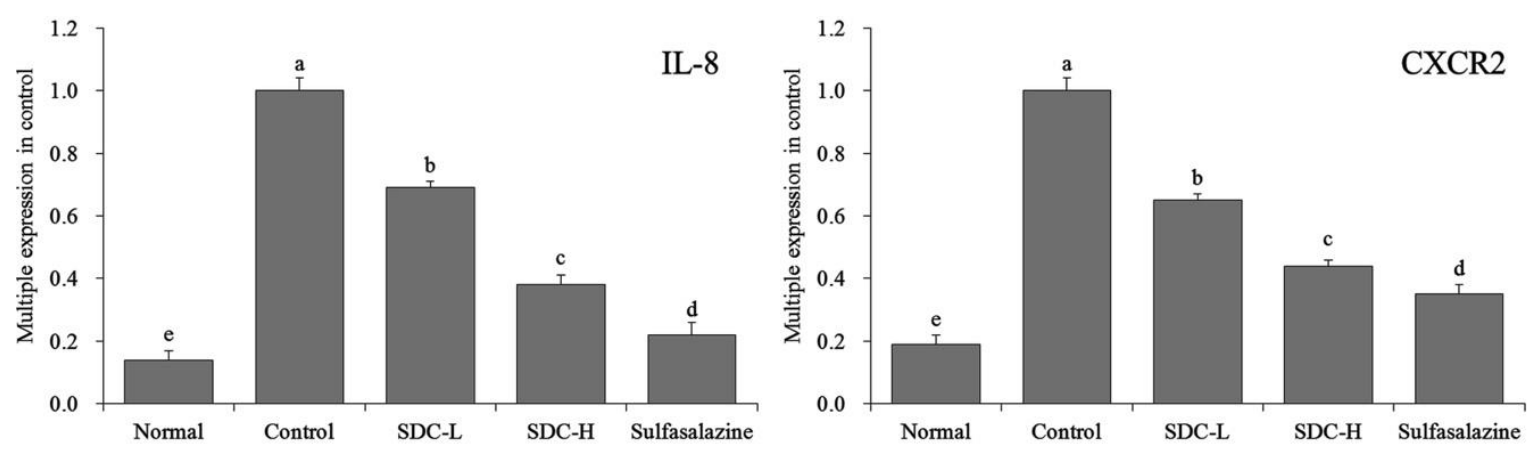

Figure 14. mRNA expression levels of interleukin-8 (IL-8) and C-X-C chemokine receptor type 2 (CXCR2) in the colon tissue of mice. Values represent the mean \pm standard deviation. ${ }^{\text {a-e }}$ Mean values with different letters in the same bars indicate significant difference $(p<0.05)$. SDC-L: $2 \mathrm{~g} / \mathrm{kg}$ Shuidouchi extract treatment; SDC-H: 4 g/ kg Shuidouchi extract treatment; Sulfasalazine: 20 mg $/ \mathrm{kg}$ sulfasalazine treatment. 
3.17. Effects of Shuidouchi on Expression Levels of IL-6, IL-12, and TNF-A Protein in Colonic Tissues of Mice with Colitis

The IL-6, IL-12, and TNF- $\alpha$ protein expression levels in the colonic tissue of mice of the normal group were weakest, but their expressions in mice of the control group were the strongest (Figure 15). Following Shuidouchi treatment, the IL-6, IL-12, and TNF- $\alpha$ protein expression were decreased when compared to the control group, and the SDC-H showed a better reducing effect than SDC-L; the effects of SDC-H were close to that of sulfasalazine.

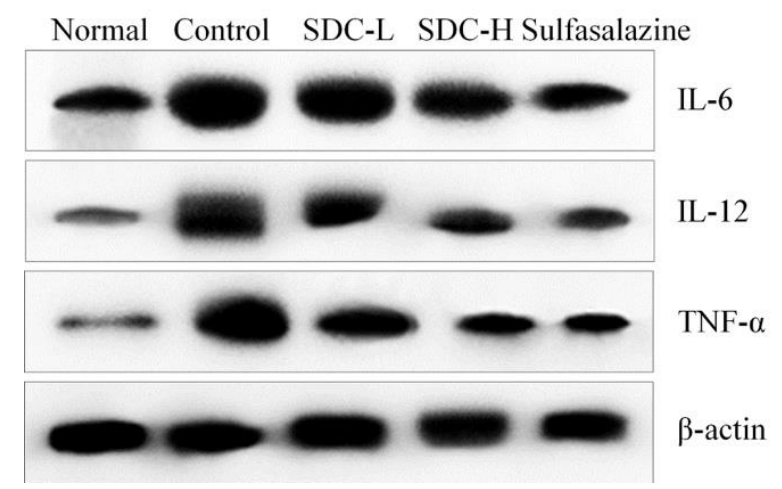

Figure 15. Protein expression levels of IL-6, IL-12, and tumor necrosis factor- $\alpha$ (TNF- $\alpha$ ) in the colon tissue of mice. SDC-L: $2 \mathrm{~g} / \mathrm{kg}$ Shuidouchi extract treatment; SDC-H: $4 \mathrm{~g} / \mathrm{kg}$ Shuidouchi extract treatment; sulfasalazine: $20 \mathrm{mg} / \mathrm{kg}$ sulfasalazine treatment.

\section{Discussion}

The DPPH method is generally used to evaluate the antioxidant effects and the antioxidant capacity of active substances. The DPPH radical with a single electron is a stable free radical. In the presence of a free radical scavenger, the free radical pairs with its single electron to reduce its absorption, and this change can evaluate the antioxidant properties of active substances [20]. ABTS ${ }^{+}$free radicals become green during oxidization. When antioxidants exist, $\mathrm{ABTS}^{+}$reacts with antioxidants and decreases the color of $\mathrm{ABTS}^{+}$free radicals. The antioxidant effect can be evaluated by the degree of fading [21]. The hydroxyl free radical is a highly active and highly toxic oxygen-free radical, which is the main factor that leads to disease and aging and it can considerably harm the body [22]. In the present study, three methods were used to evaluate the antioxidant effects of Shuidouchi that was fermented with different techniques; the highest antioxidant activity of Shuidouchi was preliminarily obtained. Studies have shown that soybean isoflavones can significantly reduce lipid peroxidation and improve the levels of the blood total antioxidant status (TAS). It can effectively scavenge free radicals, stop the chain reaction of free radicals, and prevent the oxidation of unsaturated fatty acids in lipids and endothelial membranes, thus preventing many diseases that are caused by free radicals in vivo [23]. In the current study, the soybean isoflavone content in Shuidouchi was determined, and the Shuidouchi with the best antioxidant efficacy was designed. Studies have indicated that antioxygen is gradually applied in the clinical setting. Colitis can be inhibited because antioxygen scavenging free radicals inhibit peroxidation and inflammation [24]. Soybean isoflavone is the main source of the antioxidant capacity of soybeans, which exerts a good anti-inflammatory and anti-cancer role [25]. Thus, the current study also tests the intestinal protection of Shuidouchi by designing its best antioxidant effect. To some extent, DPPH scavenging free radicals indicated the antioxidant capacity of Shuidouchi; however, the effect and utilization rate of DPPH in organisms requires further study.

Colitis is a type of intestinal inflammation, which includes ulcerative colitis, ischemic colitis, and pseudomembranous colitis. Ulcerative colitis exhibits the highest incidence, reaching 10/100,000 [26]. Studies have shown that patients with ulcerative colitis, who have a medical history of $10 \mathrm{y}$, have a greatly increased risk of colon cancer, posing a risk of almost $10 \%$ for patients with a medical history of $25 \mathrm{y}$ [27]. Food therapy for the prevention of severe intestinal diseases is currently a widely studied 
subject. In the present study, the animal model with colitis was treated with Shuidouchi that was fermented using an improved method and the preventive effects of such a method on colitis was observed. Colitis can cause the erosion and swelling of colonic mucosa, which can shorten the intestinal canal; as a result of the swollen and congested colon, the weight of the colon increases and the colon shortens, which leads to an increase in the ratio of the weight of the colon to the length of the colon. Previous studies indicated that this colon mass-to-colon length ratio is an important indicator of the degree of experimental ulcerative colitis. The higher the severity of colitis, the shorter the colon length in mice and the larger the colon mass-to-colon length ratio [28]. In the current study, mice with DSS-induced colitis showed a shorter colon and a larger colon weight-to-colon length ratio. Shuidouchi extract could significantly inhibit these changes and thus prevent colitis. The DAI index is an important index for the observation of colitis in mice. With aggravated inflammation, the DAI increases, and the DAI index decreases after the remission of colitis [28]. Consequently, colitis in mice could be relieved using Shuidouchi extract from Shuidouchi that was fermented with the improved process.

Studies have shown that the contractile effect of endothelin on blood vessels can lead to colonic mucosal erosion, which can result in ulcers in severe cases that aggravate colitis [29]. SS inhibits gastric acid secretion and suppresses gastrointestinal inflammation. Deficiency in SS can promote a large amount of gastrointestinal fluid secretion and aggravate colitis [30]. SP regulates the nervous and immune systems of the body, and the accumulation of substance $P$ in the body leads to an aggravation of colitis [31]. Excessive SP can directly result in colitis and it can inhibit colitis in antagonistic antibodies [32]. VIP can regulate the iNOS transcription in vivo, inhibiting the conversion of excessive iNOS to NO in colonic tissues and avoid intestinal mucosal damage that is caused by large amounts of NO. VIP can also inhibit disorders of the immune system that are caused by colitis [33]. Therefore, Shuidouchi fermented using this improved technique can protect the colon and prevent colitis by regulating the ET, SS, SP, and VIP.

IL-2 is a cytokine secreted by Th2 cells, which are directly related to colitis. Th2 cells can mediate the immune response to exert an effect on colitis. IL-2 can inhibit colitis by influencing Th2 cells [34]. IL-10 is a cytokine that is secreted by Treg cells, which exert an immunosuppressive effect to aggravate colitis [35]. The obtained results indicate that Shuidouchi that was fermented with this improved process can inhibit colitis by regulating the cytokines IL-2 and IL-10.

After the onset of colitis, the original aggregated neutrophils in the colon disperse, and the influx of neutrophils into the tissues markedly increases the MPO level [36]. After inflammation, free radicals, such as ROS and RNS, accumulate rapidly in vivo; consequently, the damage and toxicity of the colon tissue are further aggravated, and the degree of colitis is considerably increased [37]. Studies have shown that the GSH and SOD levels in colonic tissues decreased in response to colitis, whereas MDA, a peroxide product, increased significantly [38]. In the current study, the improved Shuidouchi process significantly influenced the MPO, SOD, GSH, and MDA levels in mice with colitis and can thus prevent colitis. The antioxidant capacity of Shuidouchi is directly reflected in the impact on the above indexes in vivo; therefore, the effects of Shuidouchi on colitis are directly related to its antioxidant effect.

The results showed that nNOS could regulate the concentration of NO in tissues and protect tissues from damage that is caused by excessive NO. Simultaneously, nNOS can control iNOS and avoid iNOS overexpression, thus resulting in an aggravation of inflammation [39]. eNOS can regulate the NO level in the body, thus maintaining the balance of NO in the body and the normal state of the colon tissues, which can regulate colon tissue injury and colitis [40]. NO is produced by two cNOS subtypes that are associated with iNOS, accelerating nitrification and oxidative damage, while also increasing inflammatory factors [41]. A high amount of iNOS can convert an equally high amount of NO, and excessive NO can lead to colonic tissue damage, resulting in the aggravation of colitis [40]. Studies have also shown that the expression pattern of iNOS is related to inflammation, and the inhibition of iNOS can reduce inflammation [41]. Simultaneously, inflammatory bowel disease (IBD) is associated with the excessive production of NO by iNOS, and the amount of NO in the intestinal tract and saliva of patients with IBD is increased when compared to control subjects [42]. Animal experiments have 
also shown that the inhibition of iNOS attenuated the DSS-induced colitis in mice [43]. The results of the present study also indicate that this improved Shuidouchi fermentation could prevent colitis by regulating the expression levels of nNOS, eNOS, and iNOS in the colon.

Colitis occurs in response to colon dysfunction and a decline in colon motility; furthermore, colitis can also cause a decrease in the number of normal interstitial Cajal cells, thus reducing colon motility, which is directly related to colitis [44]. C-Kit can maintain the number of interstitial Cajal cells and prevent the aggravation of colitis [45]. SCF also plays an important role in maintaining the number of interstitial Cajal cells. The number of interstitial Cajal cells decreases and their proliferation is affected by the impaired inflammation of the SCF/Kit signal pathway, which further aggravates colitis [44]. These results showed that enhanced expression of c-Kit and SCF mRNA in the colon could alleviate colitis and thus, Shuidouchi could prevent colitis. Simultaneously, the effects of high-concentration Shuidouchi were close to those of sulfasalazine, which is the main drug used to treat colitis.

A large number of inflammatory cells, including neutrophils and lymphocytes, were recruited into the injured tissues during the UC active phase [46]. Immune cells overcame the vascular endothelial cell barrier moving between the body fluids and tissues and involving many steps that are required for cells that flow with the body fluid. Cells are firmly adhered to the blood vessel endothelium, and the cells pass through the intercellular space of the endotheliocyte. Cells then migrate to specific tissues. During this process, cell selectivity and stable adhesion of selected cells are observed. Apart from activating and chemoattracting inflammatory cells, chemokines with increased expression can also trigger other complex inflammatory activities, such as exocytosis, the production of metalloproteinase-degrading matrix, and upregulation of oxidative bursts [47]. Chemokines control the exudation of IL-8 via intracellular signal transduction, which is a typical neutrophil chemokine and activator that mediates inflammatory responses in various ways, including colitis [48]. CINC-1 is a neutrophil chemokine of the IL-8 family, while CXCR2 is a receptor for CINC-1. CXCR2 acts as a mediator to regulate organ-to-organ interactions. Decreasing the expression of CXCR2 in tissues can effectively reduce colonic tissue damage that is caused by colitis [49]. Therefore, the experimental results indicate that Shuidouchi can inhibit colitis by downregulating the expression of CXCR2 and IL-8.

IL-6 is also known as proinflammatory cytokine and it is a widely used cytokine. It can affect inflammation, host defense, and tissue damage through humoral and cellular immune functions. Its production can be regulated by IL-1, interferon, and TNF- $\alpha$ [50]. IL-12 is an inflammatory cytokine that can induce cytotoxic activity of CTL and NK cells and promote their secretion of IFN-gamma, TNF- $\alpha$, GM-CSF, and other cytokines [51]. TNF- $\alpha$ is the earliest and most important inflammatory mediator during the process of inflammation. It can activate neutrophils and lymphocytes, increase the permeability of vascular endothelial cells, regulate the metabolic activity of other tissues, and promote the synthesis and release of other cytokines [52]. These results showed that Shuidouchi reduced these proinflammatory expression levels and inhibited colitis. In this study, mice were used for all experiments. Because there are several differences between the mouse and human genome, and because the organs are different, the results of this study can confirm the effect of Shuidouchi on colitis only to a certain extent. Therefore, it is necessary to further verify the effect of Shuidouchi on the human body. At the same time, the mechanism of Shuidouchi in the human body also requires comprehensive and in-depth experiments. As basic research, this study has played a specific theoretical role.

\section{Conclusions}

In this study, through in vitro experiments of Shuidouchi fermented under different conditions, the optimal fermentation conditions were obtained and they are listed in the following: soybeans should be soaked in twice the quantity of water for $12 \mathrm{~h}$, placed it in a glass container, and fermented at $35{ }^{\circ} \mathrm{C}$ for $48 \mathrm{~h}$. Under this condition, Shuidouchi fermentation achieved a greater antioxidant effect than that fermented under other conditions, which also contained the highest level of soybean isoflavones. To evaluate the preventive effect of Shuidouchi on colitis, a model of mice with colitis was established by DSS. The experimental results indicate that the Shuidouchi extract could effectively 
prevent experimental colitis in mice. The preventive effect of Shuidouchi on colitis is directly related to its high soybean isoflavone content, which could be the main mechanism of the intestinal protective effect of Shuidouchi. However, the experimental results remain only applicable for mice, and the mechanism of action in humans remains to be further studied.

Author Contributions: J.Z. and Q.L. performed the majority of the experiments and wrote the manuscript; Y.W., X.L., J.M., and Y.P. contributed to the data analysis; X.Z. designed and supervised the study and read the final manuscript.

Funding: This research was funded by the College Scientific Research Project of Chongqing Chemical Industry Vocational College in 2018 [HZY2018-KJ04] and the Funded Project of Young Backbone Teachers in Chongqing Colleges and Universities, China.

Conflicts of Interest: The authors declare no conflict of interest.

\section{References}

1. Yang, L.; Yang, H.L.; Tu, Z.C.; Wang, X.L. High-throughput sequencing of microbial community diversity and dynamics during Douchi fermentation. PLoS ONE 2016, 11, e0168166. [CrossRef] [PubMed]

2. Zhao, X.; Song, J.L.; Wang, Q.; Qian, Y.; Li, G.J.; Pang, L. Comparisons of Shuidouchi, Natto, and Cheonggukjang in their physicochemical properties, and antimutagenic and anticancer effects. Food Sci. Biotechnol. 2013, 22, 1077-1084. [CrossRef]

3. Zhao, X.; Li, G.J. Fermentation period and soaked water volume influences on physicochemical properties and in vitro anticancer effect of Shuidouchi. Sci. Technol. Food Ind. 2013, 34, 344-348.

4. Nagata, C.; Takatsuka, N.; Kawakami, N.; Shimizu, H. A prospective cohort study of soy product intake and stomach cancer death. Br. J. Cancer 2002, 87, 31-36. [CrossRef] [PubMed]

5. Pan, H.C.; Yang, D.Y.; Ho, S.P.; Sheu, M.L.; Chen, C.J.; Hwang, S.M.; Chang, M.H.; Cheng, F.C. Escalated regeneration in sciatic nerve crush injury by the combined therapy of human amniotic fluid mesenchymal stem cells and fermented soybean extractions. Natto. J. Biomed. Sci. 2009, 16, 75. [CrossRef] [PubMed]

6. Iwai, K.; Nakaya, N.; Kawasaki, Y.; Matsue, H. Inhibitory effect of natto, a kind of fermented soybeans, on LDL oxidation in vitro. J. Agric. Food Chem. 2002, 50, 3592-3596. [CrossRef]

7. Seo, H.R.; Kim, J.Y.; Kim, J.H.; Park, K.Y. Identification of Bacillus cereus in a chungkukjang that showed high anticancer effects against AGS human gastric adenocarcinoma cells. J. Med. Food 2009, 12, 1274-1280. [CrossRef] [PubMed]

8. Choi, Y.H.; Lim, H.; Heo, M.Y.; Kwon, D.Y.; Kim, H.P. Anti-inflammatory activity of the ethanol extraction of Chungkukjang, Korean fermented bean: 5-lipoxygenase inhibition. J. Med. Food 2008, 11, 539-543. [CrossRef]

9. Zhao, X.; Li, G.J. Influences of soaked water volume on physicochemical properties of Shuidouchi. Sci. Technol. Food Ind. 2013, 34, 217-220.

10. Jia, D.X.; Wu, Y.J.; Li, Y.Z.; Xu, W.Z. Screening and identification of Bacillus for lobster sauce fermentation. Food Sci. 2009, 30, 217-221.

11. Feng, X.; Zhao, X. Study on comparison of physicochemical properties of Natto fermented with different vessels. China Condiment 2016, 41, 77-81.

12. Suo, H.; Feng, X.; Zhu, K.; Wang, C.; Zhao, X.; Kan, J. Shuidouchi (fermented soybean) fermented in different vessels attenuates $\mathrm{HCl}$ /ethanol-induced gastric mucosal injury. Molecules 2015, 20, 19748-19763. [CrossRef] [PubMed]

13. Xu, A.Q.; Li, Z.J.; Wang, Y.L.; Liu, P. Progress in the researches on gut-health-oriented functional foods. Food Mach. 2010, 26, 158-163.

14. Zhao, M.J.; Cai, H.Y.; Jiang, Z.L.; Li, Y.; Zhang, H.; Feng, F.Q. High fat diet, gut microbiota and metabolic health. Food Sci. 2018, 39, 336-343.

15. Bibi, S.; Kowalski, R.J.; Zhang, S.; Ganjyal, G.M.; Zhu, M.J. Stability and functionality of grape pomace used as a nutritive additiveduring extrusion process. J. Food Process Technol. 2017, 8, 6.

16. Bibi, S.; Kang, Y.; Du, M.; Zhu, M.J. Maternal high-fat diet consumption enhances offspring susceptibility to DSS-induced colitis in mice. Obesity 2017, 25, 901-908. [CrossRef] [PubMed]

17. Chen, X.; Zhao, X.; Wang, H.; Yang, Z.; Li, J.; Suo, H. Prevent effects of Lactobacillus fermentum HY01 on dextran sulfate sodium-induced colitis in mice. Nutrients 2017, 9, 545. [CrossRef] 
18. Qian, Y.; Zhao, X.; Kan, J.Q. Preventive effect of resistant starch on activated carbon-induced constipation in mice. Exp. Ther. Med. 2013, 6, 228-232. [CrossRef]

19. Feng, X.; Zhao, X. Study on preventive effects of different vessels fermented Shuidouchi on $\mathrm{CCl}_{4}$ induced hepatic damage. Sci. Technol. Food Ind. 2016, 37, 338-342.

20. Finkel, T.; Holbrook, N.J. Oxidants, oxidative stress and the biology of ageing. Nature 2000, 408, $239-247$. [CrossRef]

21. Jasprica, I.; Bojic, M.; Mornar, A.; Besic, E.; Bucan, K.; Medic-Saric, M. Evaluation of antioxidative activity of croatian propolis samples using DPPH. and ABTS. ${ }^{+}$stable free radical assays. Molecules 2007, 12, 1006-1021. [CrossRef] [PubMed]

22. Harman, D. Aging: A theory based on free radical and radiation chemistry. J. Gerontol. 1956, 11, $298-300$. [CrossRef] [PubMed]

23. Kashyap, M.K.; Yadav, V.; Sherawat, B.S.; Jain, S.; Kumari, S.; Khullar, M.; Sharma, P.C.; Nath, R. Different antioxidants status, total antioxidant power and free radicals in essential hypertension. Mol. Cell Biochem. 2005, 277, 89-99. [CrossRef] [PubMed]

24. Li, H.J.; Zhou, W.; Yu, J.P. Therapeutic effects of antioxidant on inflammatory injury and relevant mechanism in patients with ulcerative colitis. Chin. J. Mod. Med. 2009, 19, 459-461.

25. Lee, C.H.; Yang, L.; Xu, Z.X.; Yeung, S.Y.V.; Huang, Y.; Chen, Z.Y. Relative antioxidant activity of soybean isoflavones and their glycosides. Food Chem. 2005, 90, 735-741. [CrossRef]

26. Jiang, Y.; Lv, Z.S. Relationship between Helicobacter pylori and ulcerative colitis. World Chin. J. Digestol. 2007, 15, 2909-2913.

27. Chen, G.R.; Zhang, Y.; Zheng, Y.Q.; Ren, D.J.; Hei, X.J. Literature analysis of recent 10 years in the treatment of ulcerative colitis using herbal enema. Asia-Pac.Tradi. Med. 2017, 13, 61-63.

28. Strober, W.; Fuss, I.J.; Blumberg, R.S. The immunology of mucosal models of inflammation. Annu. Rev. Immunol. 2002, 20, 495-549. [CrossRef]

29. Zhu, Y.P.; Lin, S.M.; Huang, S.; Luo, Z.Q. Clinical effect of No.1 Shuiliao decoction in treatment of diarrhea-predominant irritable bowel syndrome (damp-heat type) and its influence on plasma nitric oxide and endothelin. J. Guangxi Tradi. Chin. Med. Univ. 2007, 10, 10-12.

30. Li, X.; Wang, Q.; Xu, H.; Tao, L.; Lu, J.; Cai, L.; Wang, C. Somatostatin regulates tight junction proteins expression in colitis mice. Int. J. Clin. Exp. Pathol. 2014, 7, 2153-2162.

31. Mantyh, C.R.; Vigna, S.R.; Bollinger, R.R.; Mantyh, P.W.; Maggio, J.E.; Pappas, T.N. Differential expression of substance P receptors in patients with Crohn's disease and ulcerative colitis. Gastroenterology 1995, 109, 850-860. [CrossRef]

32. Goldin, E.; Karmeli, F.; Selinger, Z.; Rachmilewitz, D. Colonic substance P levels are increased in ulcerative colitis and decreased in chronic severe constipation. Dig. Dis. Sci. 1989, 34, 754-757. [CrossRef]

33. Kassim, S.K.; El Touny, M.; El Guinaidy, M.; El Moghni, M.A.; El Mohsen, A.A. Serum nitrates and vasoactive intestinal peptide in patients with gastroesophageal reflux disease. Clin. Biochem. 2002, 35, 641-646. [CrossRef]

34. Matsuoka, K.; Inoue, N.; Sato, T.; Okamoto, S.; Hisamatsu, T.; Kishi, Y.; Sakuraba, A.; Hitotsumatsu, O.; Ogata, H.; Koganei, K.; et al. T-bet upregulation and subsequent interleukin 12 stimulation are essential for induction of Th1 mediated immunopathology in Crohn's disease. Gut 2004, 53, 1303-1308. [CrossRef] [PubMed]

35. Yue, W.J.; Liu, Y.; Xu, W.; Dong, L.; Luo, X.T.; Jiang, W.R.; Sun, X.; Zhong, L.; Liu, J. The expressions of IL-2, IL-4, IL-17 and IL-10 in ulcerative colitis (UC) mucosa and its relation with disease activity. Fudan Univ. J. Med. Sci. 2012, 39, 454-459.

36. Mustafa, A.; El-Medany, A.; Hagar, H.H.; Elmedany, G. Ginkgo biloba attenuates mucosal damage in a rat model of ulcerative colitis. Pharm. Res. 2006, 53, 324-330. [CrossRef] [PubMed]

37. Osman, N.; Adawi, D.; Ahrné, S.; Jeppsson, B.; Molin, G. Probiotics and blueberry attenuate the severity of dextran sulfate sodium (DSS)-induced colitis. Dig. Dis. Sci. 2008, 53, 2464-2473. [CrossRef]

38. Fiocchi, C. Inflammatory bowel disease: New insights into mechanisms of inflammation and increasingly customized approaches to diagnosis and therapy. Curr. Opin. Gastroenterol. 2004, 20, 309-310. [CrossRef]

39. Boettger, M.K.; Uceyler, N.; Zelenka, M.; Schmitt, A.; Reif, A.; Chen, Y.; Sommer, C. Differences in inflammatory pain in nNOS-, iNOS- and eNOS-deficient mice. Eur. J. Pain. 2007, 11, 810-818. [CrossRef] 
40. Sasaki, M.; Bharwani, S.; Jordan, P.; Elrod, J.W.; Grisham, M.B.; Jackson, T.H.; Lefer, D.J.; Alexander, J.S. Increased disease activity in eNOS-deficient mice in experimental colitis. Free Radic. Biol. Med. 2003, 35, 1679-1687. [CrossRef]

41. Liu, J.; Wang, A.; Li, L.; Huang, Y.; Xue, P.; Hao, A. Oxidative stress mediates hippocampal neuron death in rats after lithium-pilocarpine-induced status epilepticus. Seizure 2010, 19, 165-172. [CrossRef] [PubMed]

42. Porras, M.; Martín, M.T.; Torres, R.; Vergara, P. Cyclical upregulated iNOS and long-term downregulated nNOS are the bases for relapse and quiescent phases in a rat model of IBD. Am. J. Physiol. Gastrointest. Liver Physiol. 2006, 290, 423-430. [CrossRef] [PubMed]

43. Youn, J.; Lee, J.S.; Na, H.K.; Kundu, J.K.; Surh, Y.J. Resveratrol and piceatannol inhibit iNOS expression and NF-kappaB activation in dextran sulfate sodium-induced mouse colitis. Nutr. Cancer 2009, 61, 847-854. [CrossRef] [PubMed]

44. Wang, X.Y.; Zarate, N.; Soderholm, J.D.; Bourgeois, J.M.; Liu, L.W.; Huizinga, J.D. Ultrastructural injury to interstitial cells of Cajal and communication with mast cells in Crohn's disease. Neurogastroenterol. Motil. 2007, 19, 349-364. [CrossRef] [PubMed]

45. Galli, S.J.; Tsai, M.; Wershil, B.K. The c-kit receptor, stem cell factor, and mast cells. What each is teaching us about the others. Am. J. Pathol. 1993, 142, 965-974. [PubMed]

46. Abron, J.D.; Singh, N.P.; Price, R.L.; Nagarkatti, M.; Nagarkatti, P.S.; Singh, U.P. Genistein induces macrophage polarization and systemic cytokine to ameliorate experimental colitis. PLoS ONE 2018, 13, e0199631. [CrossRef] [PubMed]

47. Damiani, C.R.; Benetton, C.A.; Stoffel, C.; Bardini, K.C.; Cardoso, V.H.; Di Giunta, G.; Pinho, R.A.; Dal-Pizzol, F.; Streck, E.L. Oxidative stress and metabolism in animal model of colitis induced by dextran sulfate sodium. J. Gastroenterol. Hepatol. 2007, 22, 1846-1851. [CrossRef]

48. Izutani, R.; Loh, E.Y.; Reinecker, H.C.; Ohno, Y.; Fusunyan, R.D.; Lichtenstein, G.R.; Rombeau, J.L.; Macdermott, R.P. Increased expression of interleukin- 8 mRNA in ulcerative colitis and Crohn's disease mucosa and epithelial cells. Inflamm. Bowel Dis. 1995, 1, 37-47. [CrossRef]

49. Zhang, T.; Shi, B.; Chen, J.Y.; Pan, F. Expression and significance of cytokine-induced neutrophil chemoattractant-1 and CXC chemokine receptor 2 in a rat model of colitis. World Chin. J. Digestol. 2009, 17, 78-82. [CrossRef]

50. Hozumi, H.; Russell, J.; Vital, S.; Granger, D.N. IL-6 mediates the intestinal microvascular thrombosis associated with experimental colitis. Inflamm. Bowel. Dis. 2016, 22, 560-568. [CrossRef]

51. Ebrahimi Daryani, N.; Sadr, M.; Soltani, S.; Saghazadeh, A.; Moossavi, S.; Shahkarami, S.; Farhadi, E.; Rezaei, N. Association of T helper 1 cytokine gene single nucleotide polymorphisms with ulcerative colitis and Crohn's disease. Dig. Dis. 2019, 37, 21-32. [CrossRef] [PubMed]

52. Koh, S.J.; Kim, J.M.; Kim, I.K.; Ko, S.H.; Kim, J.S. Anti-inflammatory mechanism of metformin and its effects in intestinal inflammation and colitis-associated colon cancer. J. Gastroenterol. Hepatol. 2014, 29, 502-510. [CrossRef] [PubMed]

(C) 2018 by the authors. Licensee MDPI, Basel, Switzerland. This article is an open access article distributed under the terms and conditions of the Creative Commons Attribution (CC BY) license (http:// creativecommons.org/licenses/by/4.0/). 